\title{
Historical perspective on procedures to ligate the fallopian tube for sterilization
}

\section{Thomas Ryan}

Thomas P. Ryan, "Historical perspective on procedures to ligate the fallopian tube for sterilization," Proc. SPIE 10297, Matching the Energy Source to the Clinical Need: A Critical Review, 1029705 (24 January 2000); doi: 10.1117/12.375225

SPIE. Event: Digital Optical Computing, 1990, Los Angeles, United States 


\title{
Historical perspective on procedures
}

\section{To ligate the fallopian tube for sterilization}

\author{
Thomas P. Ryan \\ Ethicon, Box 151, Somerville, NJ 08876
}

\begin{abstract}
After decades of attempts to occlude the fallopian tube thorough mechanical, cautery, and chemical techniques, no practical solution has yet attained wide clinical success and usage. An historical tour of prior techniques such as caustic chemicals, polymer injections, implants, and mechanical or thermal techniques is provided herein. Promising contemporary methods employ heat as a technique for lesioning the fallopian tube, although the original work in thermal treatment dates back to 1878 . Recent studies performed in animal models employ microwave or radiofrequency devices that have the potential to succeed as transcervical solutions, accomplishing tubal ligation without surgery. In cases where an implant is used instead of energy delivery to thermally ablate, the natural peristalsis of the fallopian tube causes these implants to migrate and become expelled. Failure equates to unwanted pregnancy or ectopic pregnancy, a pregnancy outside of the uterus. Thermal techniques have the advantage of leaving no foreign body behind and can be carefully monitored and controlled in both the temperature and time domains. The energy sources include conductive sources, laser, cryogenic, microwave and radiofrequency devices. The most promising studies utilize thermal methods with the temperature monitored and well regulated. This will assure consistent, circumferential lesion formation, occlusion of the tube through fibrosis, and clinical success.
\end{abstract}

Key words: Fallopian tube, sterilization, RF, microwave, ablation, thermal treatment, tubal ligation, radiofrequency, laser, cautery

Matching the Energy Source to the Clinical Need: A Critical Review, edited by Thomas P. Ryan,

Proc. of SPIE Vol. 10297 (Vol. CR75), 1029705 - (c) (2000) 2017 SPIE

CCC code: $0277-786 X / 17 / \$ 18 \cdot$ doi: $10.1117 / 12.375225$

195

Proc. of SPIE Vol. 10297 1029705-1

Downloaded From: https://www.spiedigitallibrary.org/conference-proceedings-of-spie on 25 Apr 2023 Terms of Use: https://www.spiedigitallibrary.org/terms-of-use 


\section{INTRODUCTION}

Widespread sterilization of men has not been accepted by many communities, so studies over the years have focused on women. To date, no nonsurgical methods have gained wide acceptance by physicians or patients worldwide. Sterilization of women by surgical occlusion of the fallopian tube is currently used by more than 100 million women of reproductive age worldwide. Voluntary surgical sterilization has become the most widely used method of family planning in both the developed and developing world (1).

Ligation of the fallopian tubes without surgery has been called the Holy Grail of gynecology and women's health. Worldwide, there are 9.2 million tubal sterilization procedures done annually. In fact surgical sterilization accounts for one-third of all contraceptive use worldwide (2). There is an enormous demand for an optimal sterilization method in both developed and developing countries (3). Although the trend has been toward more minimally invasive procedures, surgery is still required for contemporary tubal sterilization and no scientifically validated transcervical method is available (4).

Current techniques are typically done laparoscopically, that is, through 1-3 small ports under the visual guidance of a laparoscope. The tubes are "ligated" by placing a clip or band or by applying radiofrequency (RF) energy to desiccate the tube. Both the clip and band are touted as being more reversible and immediate in their effect, but due to the acute ischemia may be much more painful in the short term. An alternative is bipolar RF energy which is applied with forceps that grasp the outside of the fallopian tube, typically in three applications, to create a $3 \mathrm{~cm}$ long, contiguous desiccated region. The actual target though is the inner mucous layer, which is not visualized during the procedure. Although $3-5 \%$ of patients effectively sterilized will request a reversal, sterilization methods should be presented to the patient as a permanent method of fertility regulation (5). An alternate technique is required that would be transvaginal and obviate a surgical procedure.

An ideal sterilization procedure would involve a simple, easily learned, single procedure that would be accomplished under local anesthesia (4). Unfortunately, with available equipment, hysteroscopic and laparoscopic sterilization are expensive and require surgical skill (6), unless a simple, inexpensive system is designed. Many techniques have attempted transvaginal access into the cervix and the interior of the uterus to access the fallopian tubes from the inside. These techniques will be described in detail and include mechanical and injected implants, cautery, and controlled energy delivery.

This work will cover the historical attempts as well as contemporary microwave and RF techniques. Included are simulations of applied energy to rabbit and human fallopian tubes for the purpose of sterilization. Ultimately, obliteration of the lumen of the fallopian tube should be the clinical effect to assure the efficacy of this technique. Although there is a great need for a reliable method of female sterilization, to gain acceptance it must be inexpensive, easy to perform, and without significant side effects or complications (7), as well as safe, having a low failure rate, minimally invasive, nonhormonal, and not requiring electricity for developing countries with rural populations. 


\section{HISTORICAL PERSPECTIVE}

\subsection{Fallopian tube anatomy}

Rocca et al. (8) studied the fallopian tube in a population of women and found that the intramural segment ranged from 9 to $17 \mathrm{~mm}$ (mean $10 \mathrm{~mm}$ ) in length. The isthmus was found to be $20-30 \mathrm{~mm}$ in length with an inside diameter of $0.4 \mathrm{~mm}$ and an

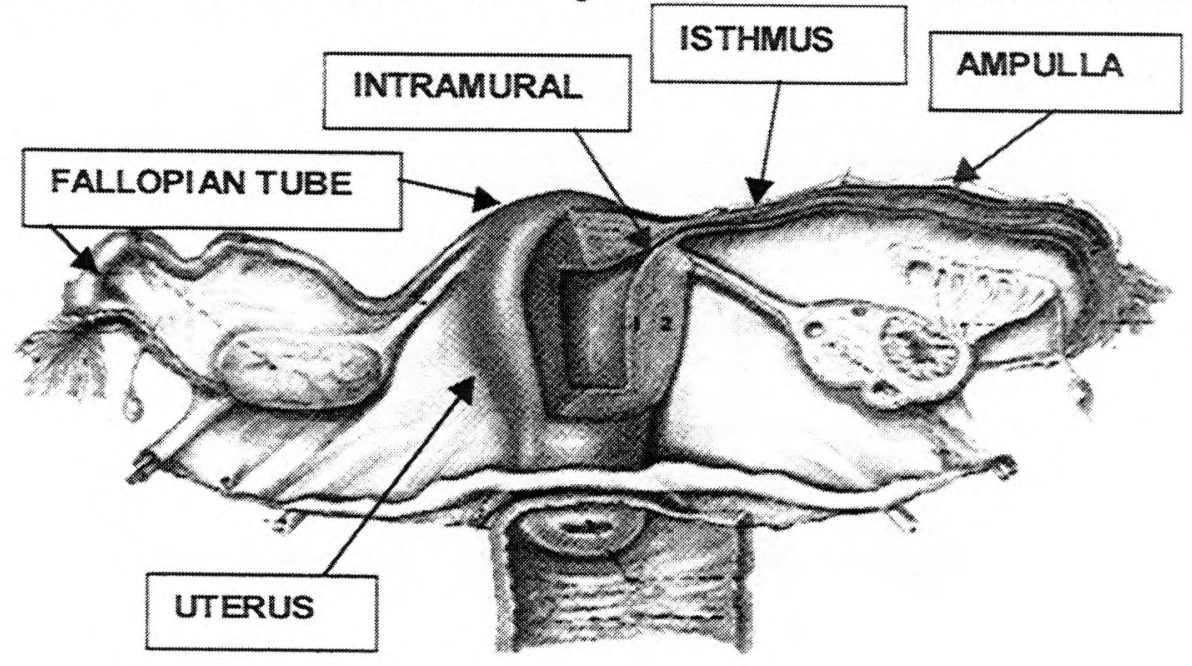

\section{FIGURE 1}

The drawing in Figure 1 depicts the fallopian tube and surrounding anatomy including the uterus, vaginal vault, ovaries, and broad ligament, the supporting structure. The fallopian tube segments begin with the tubal osteum, the entry from inside the uterus, and continues into the intramural (or cornual) section with its thick wall. It continues into the isthmus, the normal target for laparoscopic tubal ligation, and into the ampulla or fimbria section. The fimbria end (most distal) is open for egg capture from the ovary.

outside diameter of 3-4 mm. Figure 1 depicts the structure of the fallopian tube from the thick walled, small lumen, proximal portion to the thin walled, large diameter, distal section. 


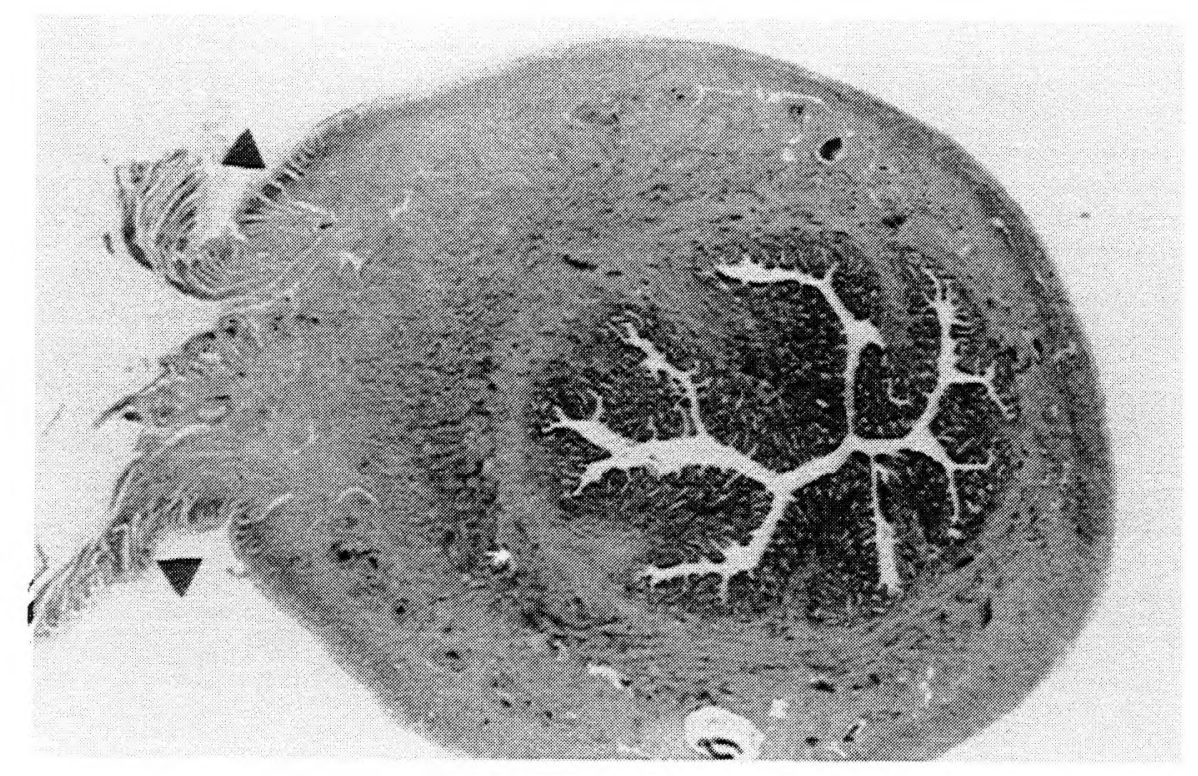

FIGURE 2

A histological specimen is shown of the crossection of normal rabbit uterine horn (H\&E stain). The muscle of the broad ligament is seen breaking the continuity of the circumference and set apart by two arrows. The horn has many irregular contours giving it a substantially large inner surface and multiple channels for a sperm of egg to pass. This presents a challenge when attempting to obliterate the lumen during the healing process. The horn mimics the human fallopian tube in general structure.

\subsection{Early attempts at transcervical sterilization}

In order to avoid a surgical procedure, transcervical access to the fallopian tubes has been an evolutionary process. One of the earliest documented attempts at transcervical sterilization was the use of a chemical to close the tubal osteum by Froriep in 1849 (69). He passed a nitric acid coated probe through the cervix to chemically stricture the tubal osteum by sclerosing the tube in a blind procedure. This was done without the modern visual guidance of scopes and fiberoptics. Although the possibility of approaching the tubal lumen via the uterine cavity was recognized in the $19^{\text {th }}$ century, it took development of the modern hysteroscope with fiberoptic technology to open up a range of non-surgical sterilization possibilities (9). Pantaleoni (10) introduced hysteroscopy to examine the uterus for intrauterine disease by inflating a rubber balloon and using a kerosene lamp as a light source. 


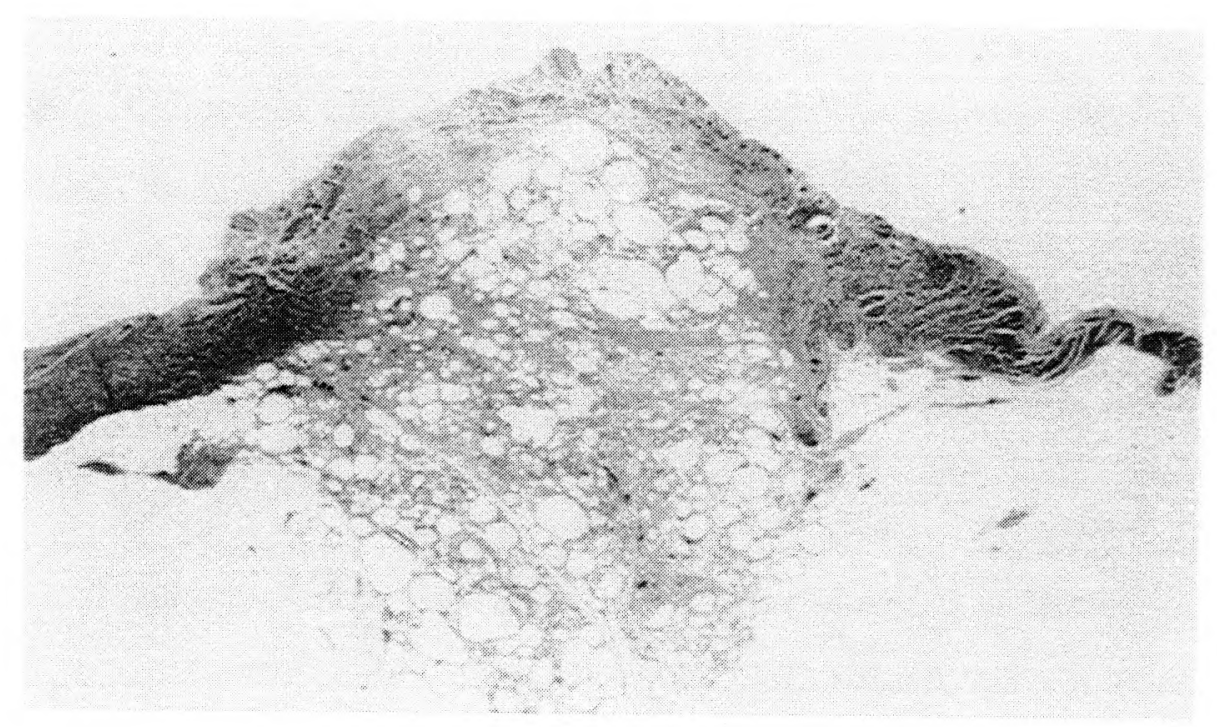

FIGURE 3

Rabbit uterine horn crossection after histological preparation and H\&E staining. The left and side structures comprise the broad ligament support structure. This is from the study by Hurst et al. (54) and resulted from thermal treatment with $R F$ energy and a 12 week healing time. The target dose was $105^{\circ} \mathrm{C}$ for 20 seconds. There were no pregnancies in this mating arm of the study.

\subsection{Plug implants}

Some of the early studies to occlude the fallopian tube were done by Hamou et al. (11), who placed a $1 \mathrm{~mm}$ diameter surgical nylon cord with a memory loop. The cord was $3 \mathrm{~cm}$ in length and the author claimed that the procedure was reversible since the cord was easily removed. A second study by Cooper et al. (12) attempted to place plugs in the fallopian tubes. Tubal spasm was encountered in $9 \%$ of the cases that prevented bilateral placement of tubal plugs.

Brundin (13) placed an implant into the fallopian tube which consisted of a nylon core containing a hydrogel. The implant was copolymerized by treatment by gamma radiation prior to implant. The hydrogel swells through uptake of bodily fluids and increases in size by a factor of 2.5 with a module of elasticity exceeding the musculature of the tubal walls. The hydrogel body then acts as a framework for ingrowth of fibroblasts and capillaries over a period of 2-3 years. The device was inserted into the intramural or cornual region of the tube. A radiopaque dye was injected and filled the fallopian tubes, indicating that the system was blocking fertilization without obliterating the lumen. There were 45 pregnancies in the clinical series averaging 4.6 pregnancies per 100 woman years. Failures were associated with the expulsion of the device. 
Smitz-Rode et al. (14) placed self-expanding microspindles under fluoroscopic guidance. The devices were $9-18 \mathrm{~mm}$ in length with an expanded diameter from 1.5 to $2.0 \mathrm{~mm}$. The devices were made from a stainless steel braid resembling a stent, with a taper on each end made by soldering a small blob on each end. Air was used to insufflate the vagina and uterus and a catheter was placed using over-the-wire techniques. The wire was then removed after catheter placement and the plug was pushed out of the catheter into the tube. One uterine horn remained untreated as the control. Three breeding cycles were performed with deliveries of offspring. Of the 10 rabbits where the device remained in place, there was one failure $(9.0-\mathrm{mm}$ long implant) and one perforation. The authors hypothesize that the implants impaired the contractility of the tube since there were no cases of lumen obstruction and no obstruction of the interior of the spindle. After insertion, the spindle straightened and stretched the lumen of the tube. Sperm may be able to pass and cause ectopic pregnancies due to the lack of obliteration of the lumen. Finally, removal is unlikely since the device is firmly implanted.

Ross et al. (15) performed a rabbit study with a coil implant in the fallopian tube. The coil was composed of a stainless steel spring coil wireguide, $3.9 \mathrm{~cm}$ in length and $0.53 \mathrm{~mm}$ in diameter. The study utilized 21 rabbits of which $34 \%$ had devices that became dislodged. Furthermore, three rabbits had a pregnancy with the coil in place. The coil typically dislodged between 5 days and 18 weeks and the total failure rate was $44 \%$.

To improve upon this, a custom microcoil was fabricated of $0.46 \mathrm{~mm}$ platinum wire with a $3 \mathrm{~mm}$ pigtail of dacron fiber at each end and also along the coil length (16). The coils were 5,6 , or $7 \mathrm{~cm}$ in length, so to span the tubal isthmus, cornual region, and part of the uterine horn. Coil placement was affected by tubal spasm. One tube remained unimplanted as the control. No pregnancies were found on the coil implant side. Histologically, atrophy and loss of mucosal epithelial cells were found with Dacron particles left behind after intentional removal. Contraceptive action may be more like an IUD since coil-induced necrosis and inflammation were seen with fibrosis in the fallopian tube and uterus. There was placental tissue in the wall of three uteri, suggesting that embryo implantation did occur but did not successfully develop.

\subsection{Plug implants and cautery}

Neuwirth et al. (17) performed a clinical study with electrocautery, alone or combined with insertion of a polyester mesh or teflon mesh. With cautery alone, the closure rate was $75 \%$. With cautery followed by insertion of a polyester mesh, the closure rate was $69 \%$. When the polyester mesh was replaced by a teflon mesh, the closure rate rose to $85 \%$. Richart et al. (18) performed a clinical study on 44 women over a five day period. The results were $84 \%$ bilateral tubal obstruction. A mesh was implanted following the cautery of the tube, but the occlusion success rate did not improve.

A more comprehensive study was done to investigate the interaction between implants and thermal insult. The combined destruction of the mucosa with insertion of a biodegradable plug was done in a rabbit series by Vancaillie et al. (7). The technique combined thermal destruction of the mucosa with insertion of a biodegradable plug afterward. The hypothesis was that the mucosa destruction provokes an inflammatory reaction and the plug guides the healing process toward occlusion instead of 
recanalization. In a rabbit model, a slit was made in the uterine horn and a $5 \mathrm{~mm}$ endoscope was inserted. The uterine horn was distended with $5 \%$ glucose and a bipolar probe inserted with a $2 \mathrm{~mm}$ diameter. A $5 \mathrm{~mm}$ long tip was placed through the operating channel and placed in the uterine-tubal junction of the rabbit. It was inserted $1.5 \mathrm{~cm}$ deep then pulled back. A power level of $4.8 \mathrm{~W}$ was applied for $5 \mathrm{~s}$, with a $2.0 \mathrm{~mm}$ length of blanching seen. No temperatures were monitored.

A plug was then inserted into the uterotubal junction, following the removal of the device. The plug was Aqualloy and was made into $10 \mathrm{~mm} \times 1 \mathrm{~mm}$ rods. Aqualloy is a mixture of 2 polymers and readily absorbs water to expand up to 40 times. Moisture causes a drug to be released, which was either platelet extract or quinicrine. Tubal occlusion was due to interruption of mucosal lining between the endometrium and endosalpinx with the contact of the plug with the area of mucosa interruption. The thermal damage due to the bipolar injury was minimal. Since the device was placed at the uterotubal junction, there was no risk of perforation and thermal damage to the bowel. Bipolar RF treatment sped up the inflammatory reaction and sealed around the plug, additionally increasing the chance that the plug remained in place. No mating experiments were done (7).

\subsection{Chemical}

The success of chemical agents to induce viable sterilization has been limited. The first difficulty is controlling the placement of the agents in the fallopian tube, a normally closed structure, and the second is the causation of chemical peritonitis. The third difficulty lies in the ability of the fallopian tube to regenerate and recanalize after a chemical insult even after extensive damage (15).

Merchant et al. $(19,71)$ did a study on 16 women with quinicrine pellets placed in the uterus at the fundus and a second group of 17 women with placement at the cornua. From 1-2 insertions were done weekly. The results from the two groups were similar with about $60 \%$ showing the tubal lumen narrowed to a slit, but not obliterated, with loss of mucosa. About $25 \%$ had a patent lumen with an intact epithelial lining and absence of inflammatory response.

El Kady et al. (20) showed $73 \%$ of women in their clinical study had bilateral occlusion following two insertions of quinicrine pallets. This increased to $94 \%$ after a third insertion. Complications included pelvic pain (8\%), bleeding (8\%), fever $(4 \%)$ and vertigo (4\%). Merchant and Probhu (19) gave a $252 \mathrm{mg}$ dose of quinicrine in their clinical study. Histologic evidence of closure was seen in the intramural segment (55\%) and isthmic segment $(6 \%)$ of the tube. When the dose was escalated to $324 \mathrm{mg}, 100 \%$ of the intramural segments and $59 \%$ of the isthmic segments were closed.

Laufe et al. (21) inserted $250 \mathrm{mg}$ quinicrine pellets transcervically. Blood studies showed that the plasma level of quinicrine peaked at three hours. Genetic toxicology tests were done which demonstrated mutagenicity. Because of this, the authors felt that regulatory agencies would not allow these devices to be used in US or European trials. Shuber (22) placed $0.6 \mathrm{ml}$ of methy 2-cyanoacrylate into the uterocornual tubal junction in a human clinical trial. The bilateral occlusion rate was $\mathbf{8 8 \%}$ when tested at 4 months with hysterosalpingography. 
A clinical trail was done by Neuwirth et al. $(23,70)$ with $0.65 \mathrm{ml}$ of methylcyanoacrylate (MCA) injected into the fallopian tube. The bilateral closure rate was $75 \%$. With one application, a $78 \%$ blockage was demonstrated by hysterosalpingograms and repeat applications increased the rate to $89 \%$. There were 25 pregnancies within 6 months of treatment. Some fallopian tubes showed no effect after MCA injection with fluoroscopy clearly showing flow of contrast agent down the tube.

\subsection{Chemical and cautery}

Sonmez et al. (24) used fibrin sealant which is typically used for its hemostasis and plugging action. In rabbit uterine horn, they combined fibrin sealant with bipolar coagulation using a $2 \mathrm{~mm}$ diameter probe, with $4.8 \mathrm{~W}$ applied for $10 \mathrm{~s}$ of RF monopolar energy. Blanching length on the outside of the tube was $2 \mathrm{~mm}$. Coagulation was applied first and then the sealant applied. Histopathologic examination of the tubes showed the following patency rates: control $(100 \%)$, fibrin only $(100 \%)$, cautery only $(72 \%)$, and fibrin and cautery (14\%). No temperatures or power levels were monitored.

\subsection{Polymer}

Some early studies experimented in filling the fallopian tube with a polymer to block the passage. Erb (25) attempted transcervical tubal occlusion by inducing a flow of catalyzed liquid silicone polymer into the fallopian tube. This created a flexible structure larger in diameter at both ends than in the isthmus and remained in place. The infusion catheter was sized at $2 \mathrm{~mm}$ diameter to prevent it from entering the fallopian tube. The mixture was silicone powder $(75 \%)$ mixed with silver powder $(25 \%)$ for improved radiographic opacity. The device combined a force gage and a screw drive to push the highly viscous fluid into the tube with a known force.

Loffer (26) also placed silicone in the fallopian tube to obtain a dumbbell configuration. Roentgenograms were performed at 3 months and showed that $19.4 \%$ were not sterilized at the first attempt, although $91.3 \%$ were eventually sterilized after repeated treatments. To accomplish this level, some patients received 2-3 applications. In follow-up, four patients demonstrated loss of one or both plugs. The difficulties in this procedure involved the silicone hardening too quickly or creating a large reflux. Some plugs became discontinuous and others migrated over time. Tubal spasm may also affect the injection of the silicone. Patients with the four "lost" silicone plugs had not become pregnant. A total of 34/206 patients had repeat procedures.

The goal of the work of Maubon et al. (27) was for successful, fluoroscopicallyguided, transcervical tubal closure. They used the rabbit as a model for pregnancy since $\mathbf{9 8 \%}$ of rabbits will have pregnancies in both uterine horns. They initially inserted a guidewire and catheter to assess tubal patency. Following this, a polymer solution was injected into the fallopian tube with an volume of $0.85 \mathrm{ml}$. In $6 / 8$ rabbits, the injectate entered the peritoneal cavity and in $3 / 8$ there was a reflux of the solute. One rabbit had a pregnancy and no evidence of the hydrogel was found in the peritoneal cavity of the genital tract. One rabbit had globs of hydrogel in the uterine horn that resembled early embryo implants. In $2 / 8$, the gel localized in the tube only and remained in a continuous plug. In the others, the gel separated into fragments causing adhesions and abscesses. The gel was also found to cause acute salpingitis. 
Matching the Energy Source to the Clinical Need / 203

\section{EARLY THERMAL TECHNIQUES}

\subsection{Conductive heating techniques}

Some of the early work to thermally lesion the fallopian tube was done by Kocks in 1878 (68) who performed cautery of the uterotubal junction. He described monitoring a crackling sound at the abdominal wall and steam exiting out of the uterus.

Hot water was introduced transcervically into the fallopian tube by Moulding and Sirotta (28) for thermal treatment. The system consisted of a steam escape line and an infusion system with needle delivery. There were two thermocouples in the line for monitoring. This study used no mating and had a histopathological endpoint. Temperatures ranged from 36.1 to $77.5^{\circ} \mathrm{C}$. A temperature of $70^{\circ} \mathrm{C}$ and flow rate of $7 \mathrm{cc} / \mathrm{min}$ was the minimum dose that destroyed a segment of the tube. Infusions of hot solution into the peritoneal cavity were done to test the reaction in case of leakage from the ends of the tubes. No adhesions resulted when temperatures were restricted to $77.5^{\circ} \mathrm{C}$. If the fluid was infused at $84.3^{\circ} \mathrm{C}$ at $3-5 \mathrm{cc} / \mathrm{min}$, the fimbrial temperature was $60.5^{\circ} \mathrm{C}$, in ex-vivo human uteri. If the flow rate was doubled, the fimbria temperature was increased to $69.4^{\circ} \mathrm{C}$. The outside wall temperature was not measured so the danger of thermal exposure to bowel, if in close proximity to the tube, was not investigated.

Rimkus and Semm (29) also used heat for attempts at transcervical sterilization. They used a blind approach and placed a probe in the intramural section of the tube with a conductive heater set at $120^{\circ} \mathrm{C}$ for $60 \mathrm{~s}$. Tissue damage was $2-3 \mathrm{~mm}$ into tissue. The zone of damage was cylindrical with an axial length of $10 \mathrm{~mm}$ and $6 \mathrm{~mm}$ diameter. No clinical results were presented.

Sheares (30) used a wire with platinum at the tip which turned cherry red when activated. The study searched for an optimum degree of cauterization when the metallic probe was placed against the cornua. A current of 2.5 A was applied and a sizzling sound was heard in the first $15 \mathrm{~s}$. At about $20 \mathrm{~s}$, a crackling or bubbling sound was heard and the device was left on for another $15 \mathrm{~s}$. No anesthetic was used and some cramping was likely. The electrode was adherent to the tissue, causing sticking and tissue debris on the electrode. The success rate was related to the number of repeat treatments (Tx): $1 \mathrm{Tx}$, $47.2 \%$ success; $2 \mathrm{Tx}, 82.4 ; 3 \mathrm{Tx}, 89.0$; and $4 \mathrm{Tx}, 91.2 \%$.

\subsection{RF monopolar techniques}

Dickenson in 1916 (31) described a method for blind cautery using a custom designed curved, unipolar electrode. He created a burn at the site of the tubal opening with an electrocautery wand. Schroeder (32) attempted to perform tubal electrocoagulation under direct hysteroscopic visualization in two patients but did not succeed in occluding the tubes. A probe was placed in the tubal osteum and electric current initiated. The procedure was monitored by determining the warmth of the uterus felt transabdominally by a hand on the lower uterus.

Hyams (33) used an acorn tip device powered by monopolar electrocautery and placed it against the tubal osteum. A current of $200 \mathrm{~mA}$ for $5 \mathrm{~s}$ duration was delivered. 
No anesthesia or pretreatment was done. The advantage claimed for this technique was no perforation of the uterus or fallopian tube since the instrument remained in the uterus. Hyams' instrument was used in a later study by Pasricha (34) and was passed into the cornual recess. A stethoscope was placed on the abdomen during RF activation to monitor the sizzling sound, followed by a crackling sound. The clinical results were $47 \%$ closure after a single treatment and $70 \%$ closure following multiple treatments. Complications included one bowel perforation and 3 cases of peritonitis in the series of 89 patients.

Lindemann (35) used monopolar cautery to attempt transcervical sterilization. The probe was $60 \mathrm{~cm}$ in length and $1 \mathrm{~mm}$ diameter. The distal section had a $5 \mathrm{~mm}$ electrode with an insulating cap and was placed $5 \mathrm{~mm}$ into the cornua. Two target doses were used with the endpoint of blanching of the tubal osteum. 1) $80-90^{\circ} \mathrm{C}, 30 \mathrm{~W}, 30-90$ $\mathrm{s}$, resulting in $100 \%$ bilateral closure. 2) $125-140^{\circ} \mathrm{C}, 5-7 \mathrm{~s}, 100 \mathrm{~W}$, resulting in $79 \%$ bilateral closure. It was found that at 12 weeks, there was good scar formation in the intramural portion of the tube and there were more failures when the procedure was done during the secretory phase of the menstrual cycle.

Sugimoto (36) also used electrocoagulation. A $1.2 \mathrm{~mm}$ diameter probe was used at 30-40 $\mathrm{W}$ for 2,3 , or $5 \mathrm{~s}$ duration. Three activations were performed. Placement was at the tubal osteum, $5 \mathrm{~mm}$, or $10 \mathrm{~mm}$ into the intramural section. Optimal tissue effects were at the following settings: $30 \mathrm{~W}(3-4 \mathrm{~s})$ or $40 \mathrm{~W}(2 \mathrm{~s})$. At $50 \mathrm{~W}$ with 2,3 , or $4 \mathrm{~s}$ activation, results were labeled as optimal.

Guerror et al. (37) performed a clinical study on 60 patients. A $5 \%$ glucose solution was injected to aid in the localization of the tubal orifice and a probe was inserted under hysteroscopic guidance. 28 of 34 had bilateral occlusion after 3 months $(82 \%)$. They concluded that blind methods were not reliable and the longer the current was passed, the greater the complication rate and severity. No hospitalization was required, but careful, frequent follow-up was recommended.

Quinones et al. (38) inserted an electrode 4-5 $\mathrm{mm}$ into the intramural segment of the fallopian tube following preliminary studies on ex-vivo uteri. Cautery was given to prehysterectomy patients at the following intervals: 1 day, 1 week, 1 month and 2 months. Tubal occlusion was demonstrated at 3 months. A modification of the tubal epithelium was seen to a depth of $8 \mathrm{~mm}$. Coagulation necrosis and changes in blood vessels were seen to a $4 \mathrm{~mm}$ depth. A total of $7 / 88$ tubes were shown to be patent on hysterogram (8\%).

Quinones et al (39) performed a clinical trial on 513 women with electrocautery. Tubal occlusion after one procedure was $85 \%$ and after a second procedure was $90 \%$. When the activation was of $4.0 \mathrm{~s}$ duration, a $26 \%$ failure rate was seen and with an extension in time to $6 \mathrm{~s}$, a $17 \%$ failure was attained.

A third clinical study was done by Quinones et al. (40). Initially, $27.8 \mathrm{~W}$ of power was applied for $4 \mathrm{~s}$ resulting in 18 failures in 70 patients $(25.7 \%)$. The time was then increased to $8 \mathrm{~s}$ to improve success. The second study included 487 patients resulting in $84.5 \%$ tubal occlusion. Finally, patients who demonstrated no tubal occlusion were retreated and the success rate climbed to $98.8 \%$. The authors state that it was preferable to perform the treatment in the first 8 days of the cycle, since following 
the 8th day of the cycle, the failure rate increased, along with increased bleeding, mucous formation, and more difficult visualization. Initially, with a ball tip electrode they had a high failure rate, but with a cylindrical electrode they improved success with better tissue contact.

Cybils (41) did a study with 22 patients. A $6 \mathrm{~mm}$ long electrode was used and $300-400 \mathrm{~mA}$ of $\mathrm{RF}$ current applied for $4-8 \mathrm{~s}$. The failure rate was $27 \%$, which was reduced to $11 \%$ following retreatment. Blanching of the mucosa was seen at the opening of the osteum. One patient had a burn and perforation of the ileum. In another case, the electrode was left behind in the patient.

March and Israel (42) stated that current techniques required penetration into the abdominal cavity for successful tubal sterilization. In the past, neither the site of application nor the extent of tissue damage could be controlled, thus advancing to intratubal techniques could add precision to the thermal treatment. They used 3 electrodes with a $2 \times 4 \mathrm{~mm}$ ball tip. The cylindrical height dimensions were $1.5 \times 6 \mathrm{~mm}$, with a teflon tip. A Hyfercator power source was used at $30 \mathrm{~W}$. Power was delivered until a white ring appeared around the electrode site at approximately $12 \mathrm{~s}$. A hysterosalpingogram was done at 3-5 months. Due to the high failure rate, they did not recommend the treatment until more advanced techniques and devices are available that overcome the major problems of safety, tubal closure failure, and subsequent pregnancies.

\subsection{Cryogenic techniques}

Droegemueller et al. (43) performed cryoablation to attain coagulation necrosis. Their target was the uterine cornua due to the lack of small devices to fit inside the lumen. The cryoprobe produced coagulation necrosis and subsequent scar formation of the cornual areas of the uterus. Preliminary testing to verify the design of the instrument, efficacy and safety testing was done in a baboon model with intentions in doing the procedure in humans.

\subsection{Laser techniques}

An attempt at transcervical tubal sterilization with a laser technique was performed by Brumstead et al. (44). A $600 \mu$ bare quartz fiber was placed hysteroscopically into the tubal osteum. At power levels of 50-60 W in $\mathrm{CW}$ mode, the tubal osteum was treated, as well as all endometrial tissue within $5 \mathrm{~mm}$ of the osteum, in a non-contact fashion. Of 24 women entered in the study, 19 completed the protocol, $41 \%$ showed bilateral patency, with $35 \%$ showing unilateral patency. The total failure rate was $76 \%$.

Grochmal et al. (45) also used a laser source for thermal treatment of the fallopian tube. By utilizing a $600 \mu$ bare fiber which was delivered hysteroscopically, 1.5 $\mathrm{cm}$ into the cornual region, a $60 \mathrm{~s}$ application was given with the fiber slowly withdrawn. The treatment utilized an Nd:YAG laser and 454 patients were done with 3 failures $(0.66 \%)$. 


\subsection{LAPAROSCOPIC TECHNIQUES}

Laparoscopic techniques for tubal sterilization presently remain in widespread use and require general anesthesia. Laparoscopic procedures may use silicone bands to tie off the tubes as demonstrated by Yoon et al. (46). A second common technique is to place a mechanical clip over the tube for occlusion as demonstrated by Hulka et al. (47). A third technique is to cauterize the fallopian tube in three places with bipolar forceps. Temperatures are not monitored.

Tucker et al. (48) performed a study with forceps applying electrocautery on the outside of the fallopian tube. In monopolar mode, complications included return electrode burns, alternate site burns in the abdominal cavity, and bowel burns. Due to safety concerns following these complications, they switched to bipolar electrodes. They still had a $4-16 \%$ failure rate. They cited a lack of general understanding of forceps and generator combination and tissue effects over time, by users. The forceps/generator combination requires different power settings for optimal performance. With a Wolf generator, 11-28 W was required. With a Valleylab generator, 18-29 W was required. The total energy should be calculated and monitored. Upon examination of the fallopian tubes, all had full thickness damage. When power was set at $50 \mathrm{~W}$, the power delivered was actually $30 \mathrm{~W}$ or less. Electrosurgical generators are specified for resistive loads, whereas the tissue is also capacitive. The authors suggest that the measure of complete tubal destruction should be correlated with of tissue impedance changes or energy delivered.

Kato et al. (49) created forceps with a temperature probe on the surface. They set the endpoint to $90 \pm 3^{\circ} \mathrm{C}$ for $30 \mathrm{~s}$ with the outside of the tube reaching $90^{\circ} \mathrm{C}$ in $6 \mathrm{~s}$. The authors felt that the temperature-controlled system was more advantageous than one sensitive to tissue impedance. Sticking to the forceps was reduced when the temperature was kept below $120^{\circ} \mathrm{C}$. The thermal dose was shown to be sufficient for coagulation.

Kato et al. (50) performed a study on rabbit uterine horns by coagulating at 2 places, $2 \mathrm{~cm}$ apart. Temperatures were $60,70,80$, or $90^{\circ} \mathrm{C}$. Times were $15,30,45$, or 60 s. A dose of $60-70^{\circ} \mathrm{C}$ for all times was insufficient for coagulation and occlusion of the lumen. Stepping up the dose to $80^{\circ} \mathrm{C}$ for $60 \mathrm{~s}$ gave nearly complete occlusion and $90^{\circ} \mathrm{C}$ for $30 \mathrm{~s}$ did occlude the lumen. This study utilized forceps that grasped the outside of the tube. No temperature measurements were made inside the tube.

There is a trend in laparoscopic tubal sterilization toward smaller instruments (scope and forceps) approaching $2.0 \mathrm{~mm}$ diameter, rather than the standard $5-10 \mathrm{~mm}$ sizes. This trend is targeted toward tubal sterilization in office-based procedures. The trend has been slow to expand due to safety concerns, reimbursement issues, and anesthesia challenges. 
Matching the Energy Source to the Clinical Need / 207

\subsection{CONTEMPORARY THERMAL TECHNIQUES}

\subsection{Microwave applications}

Microwave antennas can be used for thermal ablation of the fallopian tube due to their relatively small size and good penetration into tissue. Microwaves do not require direct electrical contact with tissue and the teflon catheter sheath prevents charring and sticking to tissue. Tissue is heated by microwave energy when the polar molecules in tissue attempt to align with the oscillating microwave field and the resultant heating is due to frictional forces in the cells that resist this realignment.

Trembly et al. (51) performed microwave heating of the rabbit uterine horn for the purposes of occlusion to mimic the human fallopian tube. A monopole antenna was inserted into a catheter to thermally ablate the uterine horn. The length of the monopole antenna was chosen to operate near resonance by considering factors such as tissue type and dimensions, microwave frequency, antenna diameter, catheter thickness, and air gap. The antenna is $1.6 \mathrm{~mm}$ diameter, operated at $915 \mathrm{MHz}$ and placed in a $2.2 \mathrm{~mm}$ OD catheter. An external catheter was attached to allow for tissue temperature measurement by a fiberoptic probe. Another variation of the antenna was a choke design to better define the heating zone. The uterine horn was isolated from the adjacent bowel and bladder by saline filled balloons to absorb the electric field. Rabbits were treated to 65$70^{\circ} \mathrm{C}$ for $5-10$ minutes. Rabbits were survived for 31 days. The lesion lengths were $3.8 \pm$ $1.5 \mathrm{~cm}$. The center of the lesion was $1.6 \mathrm{~cm}$ from the distal antenna tip. The lesions were not circumferential, but instead were $1 / 4$ to $1 / 2$ of arc. There was no charring in the tissue after heating. Due to bowel blanching in early experiments, the bowel was thermally insulated from the treatment site. Acutely, the histopathology showed a reduced circumference of the treated segment. At 30 days, some lumen obliteration was seen.

\subsection{RF bipolar applications}

Manganiello et al. (52) did a study with RF ablation on a feline model. The uterine horn was felt to be similar in size and shape to the isthmic segment of the human fallopian tube. Similarity in size and anatomy was demonstrated. They attempted to occlude the uterine horn by thermal damage leading to fibrosis. The surface of the applicator charred and prevented further heating and was thus unable to occlude the horn. The bipolar design utilized a pair of $1.0-\mathrm{mm}$ electrodes separated by $1 \mathrm{~mm}$. A second catheter had $3 \mathrm{~mm}$ electrodes separated by $3 \mathrm{~mm}$. Animals were treated in the following arms: $1 \mathrm{~W}, 10 \mathrm{~s}$; or $1 \mathrm{~W}, 60 \mathrm{~s}$. The results are outlined in Table 1 .

The group with single treatments failed to occlude the uterine horn. One lumen was partially occluded and there was thermal damage in the endometrium and myometrium. The group with two or three contiguous treatments showed five completely occluded horns and two partially occluded. Extensive uterine wall fibrosis was seen in histology. With the group treated with the longer electrodes, one horn was completely occluded and one partially occluded. 


\begin{tabular}{|l|l|l|l|l|}
\hline $\begin{array}{l}\text { Number } \\
\text { of lesions }\end{array}$ & Power (W & Time (s) & $\begin{array}{l}\text { Electrode } \\
\text { length }(\mathbf{m m})\end{array}$ & Results \\
\hline 1 & 1 & 10 & 1 & $3 \mathrm{~mm}$ lesion \\
\hline 1 & 1 & 20 & 1 & $3 \mathrm{~mm}$ lesion \\
\hline 1 & 1 & 60 & 1 & $3 \mathrm{~mm}$ lesion \\
\hline 2 & 1 & 60 & 1 & $6 \mathrm{~mm}$ lesion \\
\hline 3 & 1 & 60 & 1 & $9 \mathrm{~mm}$ lesion \\
\hline 1 & 1 & 180 & 3 & $9 \mathrm{~mm}$ lesion \\
\hline
\end{tabular}

TABLE 1

This shows the results of the study by Manganiello et al. (52) of lesioning the uterine horn in a feline model. Applied power and time of activation are shown as well as electrode length for a bipolar RF catheter activated at $500 \mathrm{kHz}$. Lesion length is also shown as measured at the surface.

The attempt here was to provide a transcervical treatment to occlude the fallopian tube by destroying the epithelial surface, and damaging the submucosa and muscularis resulting in collapse, fibrosis, stricture, and occlusion of the lumen. It is not known whether the regenerative capabilities of the feline uterine horn exceed the human fallopian tube. Examination of the uterine horn showed that the tissue between the electrodes was desiccated and prevented the continuation of RF delivery. The tissue impedance went to an infinite value as the desiccation proceeded and prevented uniform energy delivery. Temperatures were not measured or controlled.

Hurst et al. (53) performed in-vitro and in-vivo work on porcine fallopian tubes. They used an RF catheter prototype in 114 in-vitro studies to determine the optimal thermal dose with a bipolar electrode. The catheter consisted of two cylindrical electrodes separated by $5 \mathrm{~mm}$ with a thermocouple placed between the electrodes in the catheter. Power requirements were from 10-15 W at $500 \mathrm{kHz}$. Power was applied endotubally to avoid heating the outside of the tube excessively and harming adjacent structures. Power was also kept low to avoid charring of the tube or perforation due to excessive steam formation. Temperatures ranged from $70-120^{\circ} \mathrm{C}$ and times from $5-60 \mathrm{~s}$. Times greater than $20 \mathrm{~s}$ had no additional effect on the lesion length. Temperatures less than $90^{\circ} \mathrm{C}$ showed lack of a good lesion length and transmural penetration of the tube. A dose of $20 \mathrm{~s}$ and $95-105^{\circ} \mathrm{C}$ was considered optimal.

Once this dose was determined, a $1.5 \mathrm{~mm}$ diameter electrode was used in a Yucatan minipig model to create an $8 \mathrm{~mm}$ lesion or $19 \mathrm{~mm}$ lesion with 2 contiguous activations. Proximal and distal lesions were made in some cases in the isthmic or fimbrial segments, respectively. Three weeks were allowed for healing. At sacrifice, 8/11 tubes demonstrated hydrosalpinx, a swelling of the tubes due to entrapment of the naturally occurring mucosal secretions. The hydrosalpinx implied complete occlusion of both proximal and distal treatment sites. Histopathology demonstrated that complete occlusion occurred in 12/22 treated sites with scar tissue and coagulated epithelium evident. A narrowing was seen at 9/22 sites and 1/22 was open. The bipolar catheter 
electrode limited conduction of current to within the fallopian tube. The tubes that were only treated on one end showed no hydrosalpinx.

More recently, Hurst et al. (54) performed a longer survival study on rabbits with mating and pregnancy endpoints. A bipolar catheter was used with a dose of 95 or $105^{\circ} \mathrm{C}$, with a $10 \mathrm{~s}$ rise to target temperature and a $10 \mathrm{~s}$ steady-state hold. Following lesioning, mating was done at either 4 or 12 weeks. Table 2 shows the results (\# pregnant refers to the number of uterine horns pregnant). There were three control arms: no surgery; surgery and manipulation of organs but no devices; and surgery, manipulation of organs and placement of devices. A bipolar catheter with $5.0 \mathrm{~mm}$ electrodes spaced 5.0 $\mathrm{mm}$ apart was used in the fallopian tube treatments. A larger diameter version was used in the uterine horn treatments due to the larger inner diameter. Lastly, bipolar forceps were clamped on the outside of the uterine horn and activated, as done on the human fallopian tube during laparoscopic surgery. Three contiguous activations were done. A normal uterine horn is depicted in Figure 2, showing a thick muscular wall with an interior with a large surface area due to the many passages. Figure 3 depicts an ablated uterine horn with an intact broad ligament.

\begin{tabular}{|l|c|l|}
\hline TREATMENT & $\begin{array}{l}\text { \#PREGNANT } \\
\text { TOTAL }\end{array}$ & TREATMENT DETAILS \\
\hline Non-surgical control & $7 / 10$ & No surgery \\
\hline Laparotomy only & $12 / 18$ & Surgery, exposure of tube and horn \\
\hline Sham heating & $12 / 18$ & Bipolar catheter inserted, no heating \\
\hline $95^{\circ} \mathrm{C}$, endotubal & $0 / 19$ & $95^{\circ} \mathrm{C}$ inside fallopian tube, $20 \mathrm{~s}$ \\
\hline$<95^{\circ} \mathrm{C}$ endotubal & $1 / 1$ & $<95^{\circ} \mathrm{C}$ inside fallopian tube, $20 \mathrm{~s}$ \\
\hline $105^{\circ} \mathrm{C}$ endotubal & $0 / 20$ & $105^{\circ} \mathrm{C}$ inside fallopian tube, $20 \mathrm{~s}$ \\
\hline $105^{\circ} \mathrm{C}$ endouterine & $0 / 20$ & $105^{\circ} \mathrm{C}$ inside uterine horn, $20 \mathrm{~s}$ \\
\hline Bipolar forceps & $0 / 10$ & Kleppinger forceps, 3 activations, 30 s each \\
\hline
\end{tabular}

TABLE 2

Table 2 shows the breakdown according to study arm in the study by Hurst et al. (1999). Results of the mating study are expressed as number of pregnancies and some details of the treatment are given.

There was one treatment where the temperature did not attain the $95^{\circ} \mathrm{C}$ target. Histology showed that in this specimen, no grossly visible lesion was seen and the tube was widely open. This was the only failure in the treatment group with pregnancies. This was a case of an RF electrode malfunction where the target temperature and time was not reached, thus the structure was thermally underdosed.

In the $95^{\circ} \mathrm{C}$ treatment group, lesions were $0.8-1.6 \mathrm{~cm}$ long. At 4 weeks and 8 weeks $5 / 10$ and $8 / 10$ fallopian tubes had obliteration of the lumen, respectively. In the 
$105^{\circ} \mathrm{C}$ treatment group, lesions were $0.7-2.5 \mathrm{~cm}$ long. At both 4 and 12 weeks, $8 / 10$ showed obliteration of the lumen. In the $105^{\circ} \mathrm{C}$ group where the uterine horn was treated, the lumen was obliterated in 20/20. With bipolar forceps on the outside of the uterine horn or fallopian tube, $8 / 10$ had the lumen obliterated and $2 / 10$ showed a narrow channel in the uterine horn. All pregnancies were associated with widely open lumens. There were no pregnancies where the fallopian tubes or uterine horns contained small single or multiple channels buried in scar tissue. In the $95^{\circ} \mathrm{C}$ group, more residual, smooth muscle was observed along with fewer total obstructions than the $105^{\circ} \mathrm{C}$ group. Although fat necrosis in the $95^{\circ} \mathrm{C}$ group was minimal, it was extensive in the $105^{\circ} \mathrm{C}$ group of fallopian tube treatments. Sclerosis of feeding vessels was seen in the $105^{\circ} \mathrm{C}$ group. Figure 4 shows the gross pathology of a rabbit with a missing uterine horn segment resulting from treatment.

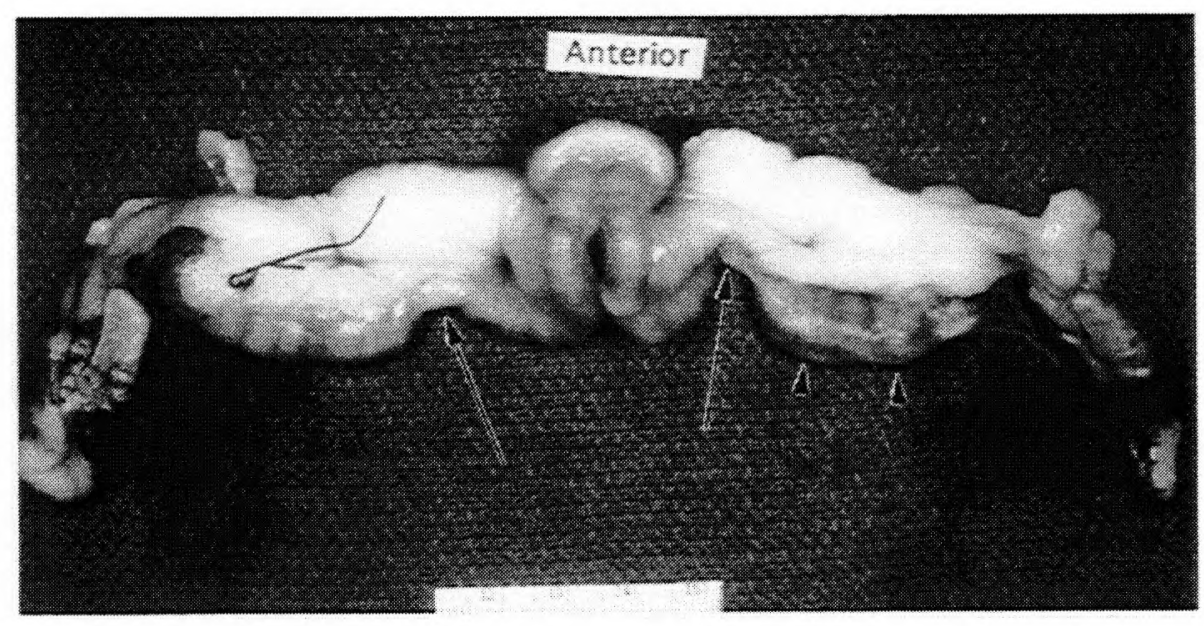

\section{FIGURE 4}

This figure depicts the gross pathology of the rabbit vagina, uterine horns and fallopian tubes. In this sample, the uterine horns were treated from the inside by an endotubal catheter. The results after 3 months of healing was a gap in the uterine horn, depicted by long arrows, in the location of the thermal treatment. A swelling of a segment of horn is shown by short arrows. 
Matching the Energy Source to the Clinical Need / 211

\section{NUMERICAL SIMULATIONS}

In order to study the lesion lengths and temperature distributions with varying electrode lengths and spacing, a numerical model was set up. In the model, the rabbit and human fallopian tube were outlined in a finite element mesh, with a lumen and either muscular wall (human) or fat layer (rabbit). Parameter values of perfusion, thermal conductivity, and electrical conductivity were varied with temperature at each element.

A voltage was applied between the electrodes for a $20 \mathrm{~s}$ interval. Lesions produced by RF energy application resulted in ablation zones that depended on the temperature distribution resulting from the electric field in the tissue layers. Although other works in the literature have modeled heating in tissue, the temperatures achieved were, for the most part, in the hyperthermia range of $40-55^{\circ} \mathrm{C}(72,73)$, typically with temperatures limited to $45^{\circ} \mathrm{C}$ maximum. This temperature limit simplified the model since the initial thermal and electrical properties of tissue were assumed constant. The system being modeled raises tissue temperature into the range of $60-110^{\circ} \mathrm{C}$ and greater, where tissue desiccates and electrical properties change substantially (55). In addition, if temperatures exceed $41^{\circ} \mathrm{C}$, damage to living tissue is a function of both temperature elevation and duration of exposure (56). Since values of electrical conductivity with changing temperatures at $500 \mathrm{kHz}$ are not found in the literature, measurements of the electrical conductivity over time at various temperatures were undertaken as input into the model $(57,67)$. Other works that assume changes in conductivity with temperature, assume that conductivity increases $2 \% /{ }^{\circ} \mathrm{C} \mathrm{(58)}$, up to $100^{\circ} \mathrm{C}(59)$.

Thermal properties also vary with temperature, and measurements were made in the laboratory in collaboration with the University of Colorado (Roop Mahajan, personal communication). Thermal conductivity as a function of temperature was placed in a table for use in the simulation.

Having a blood flow or perfusion term in the model, especially one that can be varied with time or temperature is important. The tissue perfusion term is rate of mass flow of blood per unit mass of tissue. Flow is considered to occur at the capillary level and due to the convoluted nature of these capillary beds, causes it to be non-directional (60). Blood perfusion is also a temperature-dependent function in that normal tissue may increase perfusion initially with rise in temperature due to vasodilatation and opening up of capillary beds. Tumor tissue has abnormal vasculature and thus cannot respond to temperature rise. Lastly, it has been shown that our own experiments showed that blood irreversibly coagulates at $60^{\circ} \mathrm{C}(55)$.

Modeling code was developed $(57,61)$ and allowed thermal and electrical properties to vary with temperature, time, or location. It simulated both RF devices that deposit power in tissue and purely conductive heating devices. It was based on the bioheat equation (62) as shown below in cylindrical coordinates (see Eq. 1). 


$$
\begin{aligned}
& \rho_{\mathrm{t}}(\mathrm{r}, \mathrm{z}, \mathrm{T}) \mathrm{c}_{\mathrm{t}}(\mathrm{r}, \mathrm{z}) \partial \mathrm{T}(\mathrm{r}, \mathrm{z}, \mathrm{t}) / \partial \mathrm{t}=\nabla\left(\mathrm{k}_{\mathrm{t}}(\mathrm{r}, \mathrm{z}, \mathrm{T}) \nabla \mathrm{T}\right) \\
& -\mathrm{c}_{\mathrm{b}}(\mathrm{T}) \rho_{\mathrm{b}} \mathrm{m}(\mathrm{r}, \mathrm{z}, \mathrm{T}) \rho_{\mathrm{t}}\left(\mathrm{T}-\mathrm{T}_{\mathrm{b}}\right)+\mathrm{Q}_{\mathrm{p}}(\mathrm{r}, \mathrm{z}, \mathrm{t})+\mathrm{Q}_{\mathrm{m}} \quad(\mathrm{EQ} .1) \\
& \rho_{t, b}=\text { density of tissue, blood }\left(\mathrm{kg} / \mathrm{m}^{3}\right) \\
& c_{t, b}=\text { specific heat of tissue, blood }\left(\mathrm{W} \mathrm{s} / \mathrm{kg} /{ }^{\circ} \mathrm{C}\right) \\
& k_{t}=\text { tissue thermal conductivity }\left(\mathrm{W} / \mathrm{m} /{ }^{\circ} \mathrm{C}\right) \\
& m=\text { tissue perfusion }(\text { flow rate of blood/unit mass })\left(\mathrm{m}^{3} / \mathrm{kg} \mathrm{s}\right) \\
& Q_{p}=\text { power absorbed/ unit volume tissue }\left(\mathrm{W} / \mathrm{m}^{3}\right) \\
& Q_{m}=\text { metabolic heating/ unit volume tissue }\left(\mathrm{W} / \mathrm{m}^{3}\right) \\
& T=\text { temperature }\left({ }^{\circ} \mathrm{C}\right) \\
& t=\text { time (s) } \\
& Q_{m} \text { is assumed to be small and is neglected. }
\end{aligned}
$$

The following assumptions were made in the model:

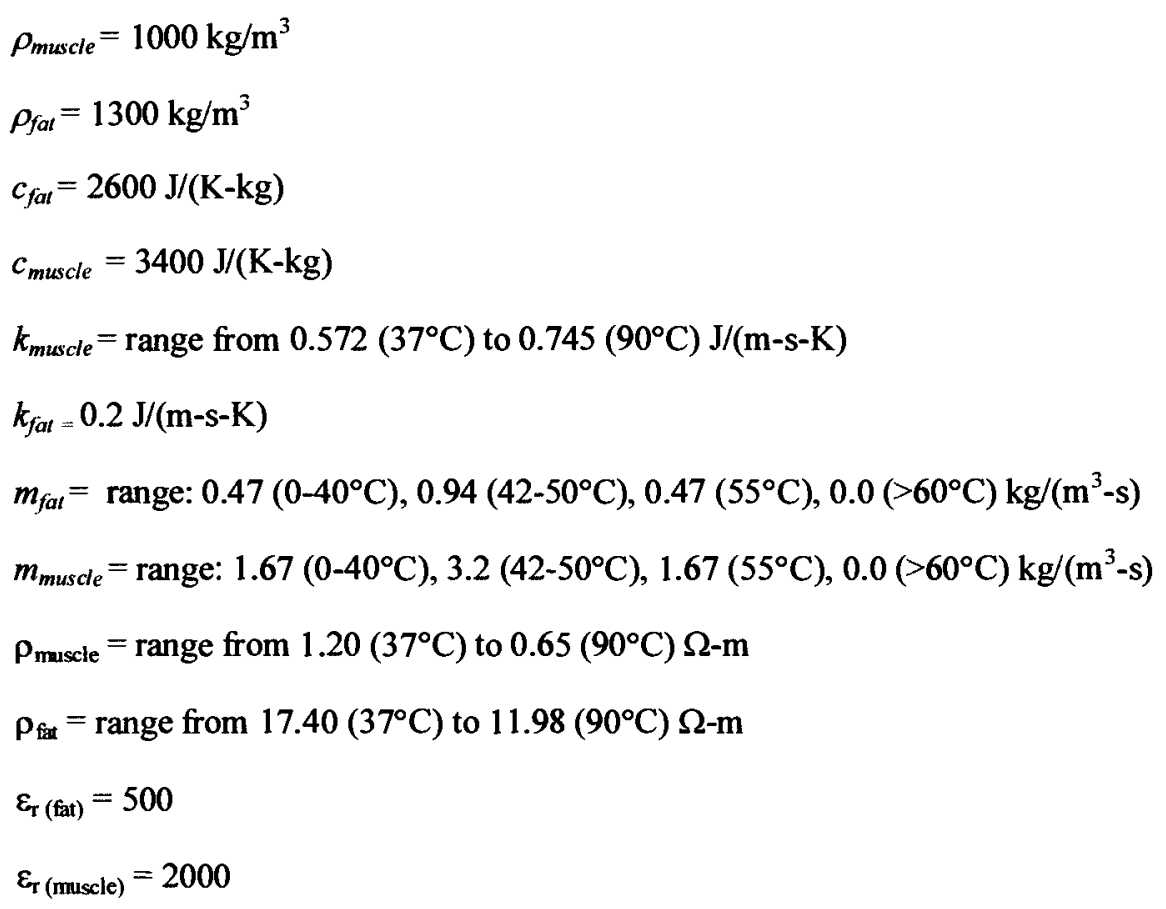




\begin{tabular}{|l|l|l|l|l|l|l|}
\hline $\begin{array}{l}\text { File } \\
\text { Number }\end{array}$ & $\begin{array}{l}\text { Electrode } \\
\text { Length } \\
(\mathbf{m m})\end{array}$ & $\begin{array}{l}\text { Electrode } \\
\text { Spacing } \\
(\mathbf{m m})\end{array}$ & $\begin{array}{l}\mathbf{T}_{\max } \\
\left({ }^{\circ} \mathbf{C}\right)\end{array}$ & $\begin{array}{l}\text { Length Of } \\
\mathbf{5 5}{ }^{\circ} \mathbf{C} \\
\text { Contour at } \\
\mathbf{2} \mathbf{m m} \text { Depth } \\
(\mathbf{m m})\end{array}$ & $\begin{array}{l}\text { Voltage } \\
\text { During } \\
\text { Ramp up } \\
(\mathbf{V})\end{array}$ & $\begin{array}{l}\text { Voltage } \\
\text { During } \\
\text { Steady } \\
\text { State } \\
(\mathbf{V})\end{array}$ \\
\hline 1L & 5 & 5 & 95 & 0.9 & 57.0 & 28.6 \\
\hline 1M & 5 & 5 & 130 & 1.8 & 60.2 & 31.4 \\
\hline IM1 & 5 & 3 & 105 & 1.3 & 40.0 & 25.2 \\
\hline 1M2 & 5 & 1 & 99 & 0.5 & 22.4 & 17.4 \\
\hline 1M3 & 5 & 7 & 147 & 2.1 & 88.4 & 30.6 \\
\hline 1M4 & 5 & 9 & 152 & 2.6 & 129.2 & 20.0 \\
\hline $1 \mathrm{M} 5$ & 1 & 5 & 163 & 1.2 & 58.5 & 33.0 \\
\hline 1M6 & 3 & 5 & 162 & 1.4 & 59.4 & 32.8 \\
\hline $1 \mathrm{M} 7$ & 7 & 5 & 124 & 2.0 & 59.0 & 31.4 \\
\hline $1 \mathrm{M} 8$ & 9 & 5 & 122 & 2.1 & 60.6 & 31.8 \\
\hline
\end{tabular}

TABLE 3

Table 3 depicts the results from the numerical model where electrode axial length and spacing was varied. Electrode length and spacing ranged from 1.0 to $9.0 \mathrm{~mm}$. The voltage is given in the initial stage to bring up the control temperature to $95^{\circ} \mathrm{C}$ in 10 seconds. The second voltage is the value required to sustain the target temperature during the second 10 second portion of the treatment. $T_{\max }$ is the maximum temperature at any location at 20 seconds, often in the proximity of the electrode where the electric field is concentrated due to discontinuities. As a comparison in performance among runs, the axial length is measured at a depth of $2 \mathrm{~mm}$ in tissue that is at $55^{\circ} \mathrm{C}$ or greater, presumably the temperature required to irreversibly damage tissue.

Results show that the rabbit model shows discontinuities in the electric field in Figure 5 due to fat/muscle interface. This also affects the power distribution seen in Figure 6 . Contrast this to Figure 7 which depicts the electric field in a human fallopian tube with all muscular walls. The power density shown in Figure 8 extends along the electrode locations. Figures 9 and 10 show temperature distributions at $20 \mathrm{~s}$ in a rabbit and human fallopian tube, respectively. As in all the simulations, the temperature probe between the electrodes in the catheter is raised to $95^{\circ} \mathrm{C}$ in $10 \mathrm{~s}$ and held for another $10 \mathrm{~s}$. The electrode locations are shown under the $\mathrm{z}$-axis in each figure. Figures 9-18 depict various scenarios for electrode length and spacing. Figure 19 shows the temperature rise in the catheter as well as in tissue during a treatment at depths from 0.0 to $5.0 \mathrm{~mm}$. 


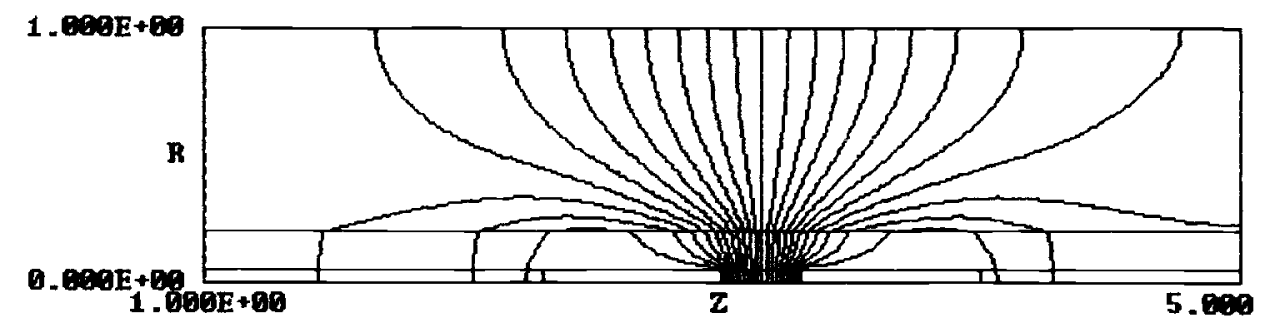

\section{FIGURE 5}

Lines of constant electric field for a rabbit fallopian tube in a simulation in cylindrical coordinates. The tube has an initial muscular layer and then an outer fat layer. The discontinuity of the contours is seen at this boundary. Frequency is $500 \mathrm{kHz}$ for a bipolar RF electrode pair. The layers are catheter, fat, and muscle, starting at $r=0$.

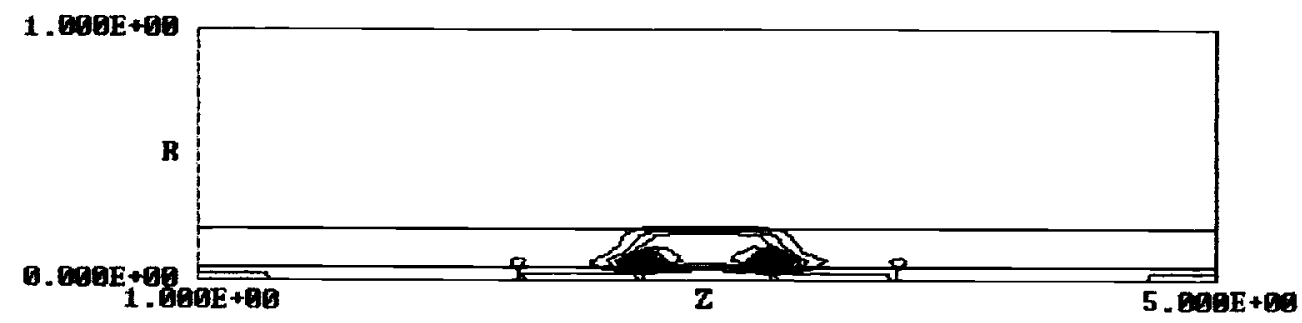

\section{FIGURE 6}

Power density is shown for a rabbit fallopian tube in a simulation in cylindrical coordinates. The tube has an initial muscular layer and then an outer fat layer. Frequency is $500 \mathrm{kHz}$ for a bipolar RF electrode pair. The layers are catheter, fat, and muscle, starting at $r=0$. 


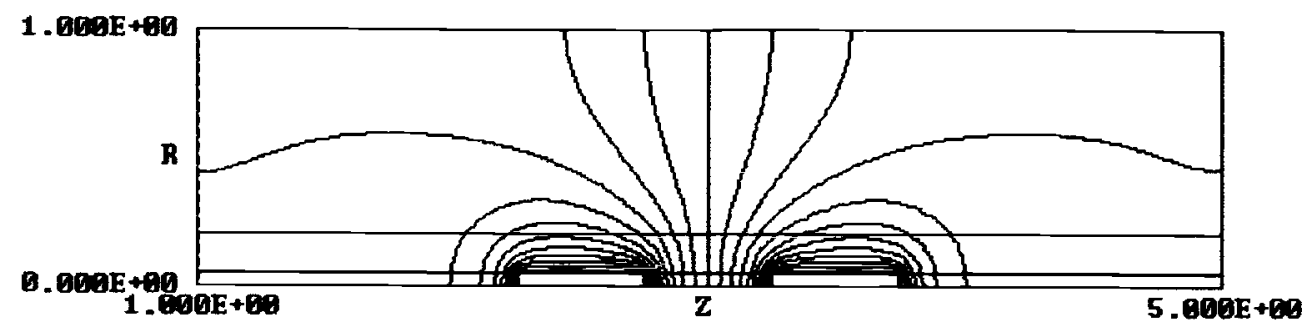

FIGURE 7

Lines of constant electric field for a human fallopian tube in a simulation in cylindrical coordinates. The tube is considered to be of a muscular layer. A catheter resides inside the tube to carry the bipolar RF electrodes. The frequency is $500 \mathrm{kHz}$. The layers are catheter and muscle, starting at $r=0$.

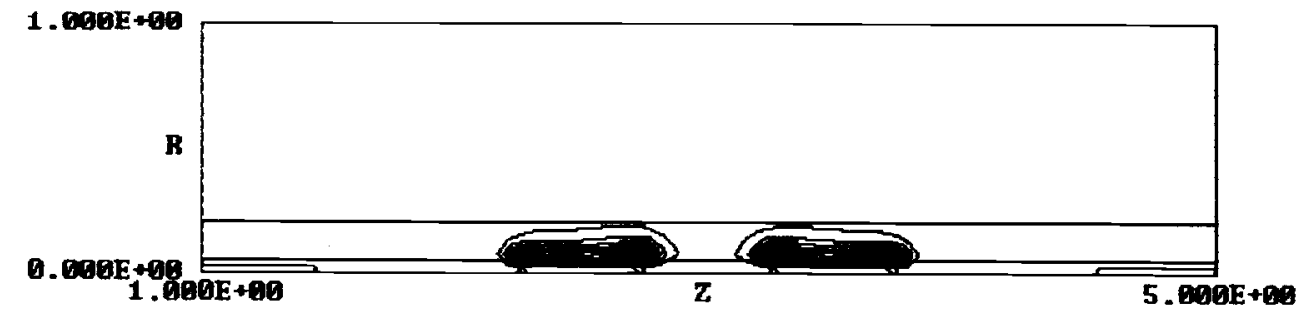

FIGURE 8

Power density is shown for a human fallopian tube in simulation in cylindrical coordinates. The tube is considered to be of a muscular layer. Frequency is $500 \mathrm{kHz}$ for a bipolar RF electrode pair. The layers are catheter and muscle, starting at $r=0$. 


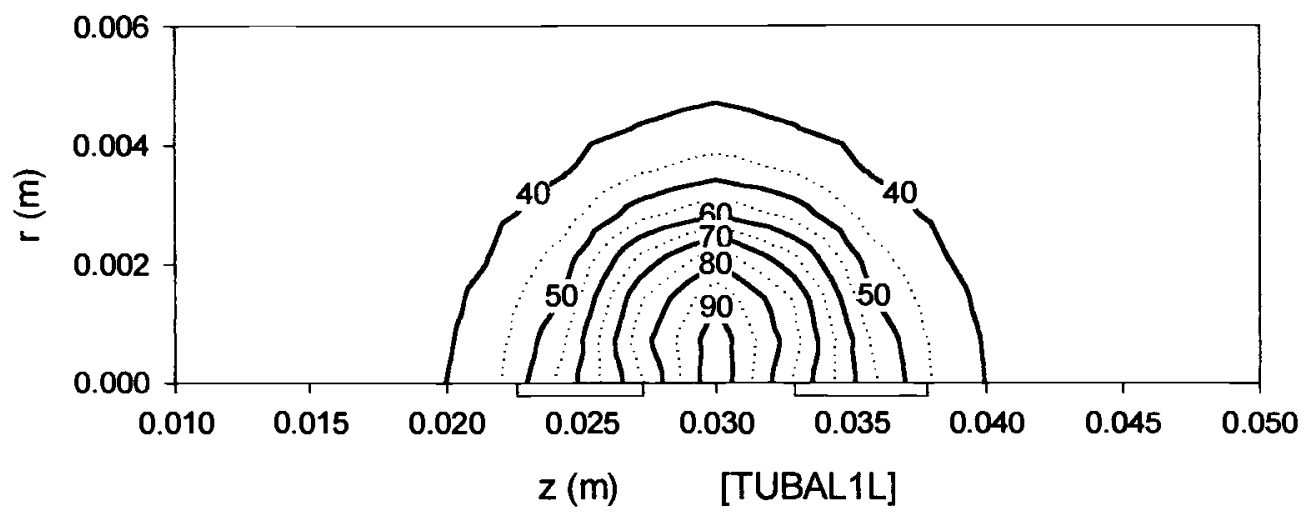

FIGURE 9

Results in a rabbit fallopian tube simulation in cylindrical coordinates. Temperature isotherms at the end of treatment (20 s) for bipolar $R F$ electrodes of $5 \mathrm{~mm}$ length and 5 mm spacing are shown. Applied voltage at the end of treatment was $28.6 \mathrm{~V}$. The horizontal boxes under the z-axis denote the electrode positions.

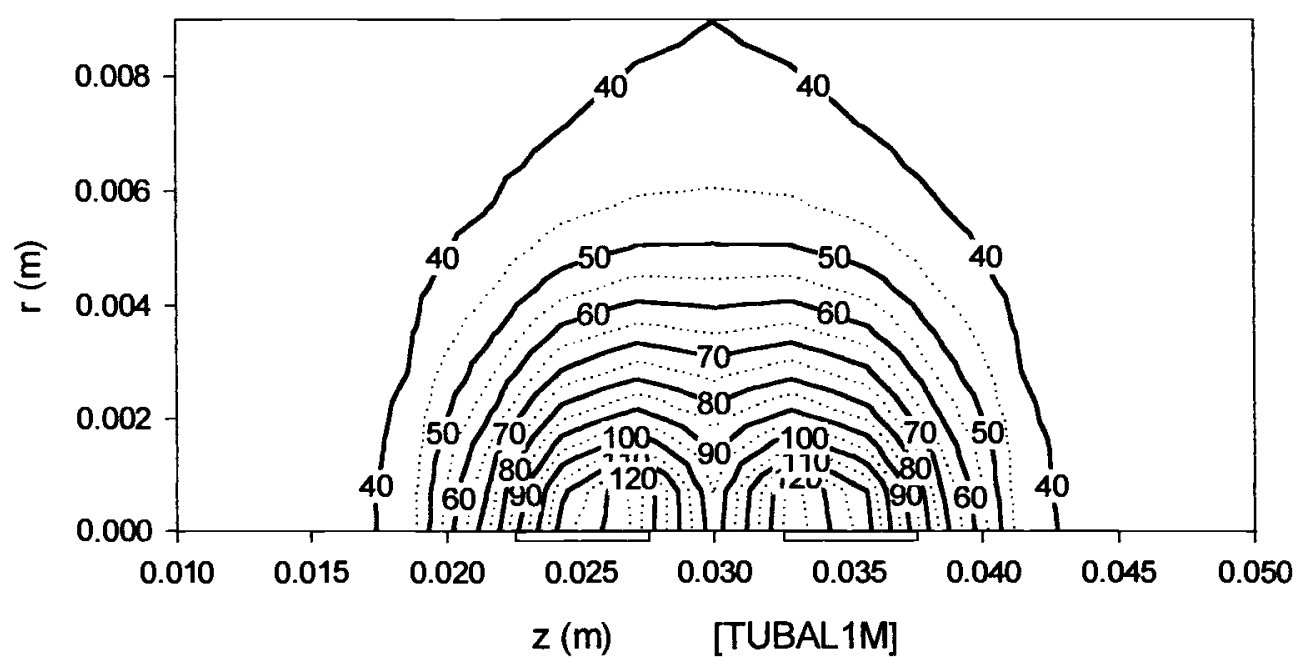

FIGURE 10

Results in a human fallopian tube simulation in cylindrical coordinates. Temperature isotherms at the end of treatment (20 s) for bipolar RF electrodes of $5 \mathrm{~mm}$ length and 5 $\mathrm{mm}$ spacing are shown. Applied voltage at the end of treatment was $31.4 \mathrm{~V}$. The horizontal boxes under the z-axis denote the electrode positions. 


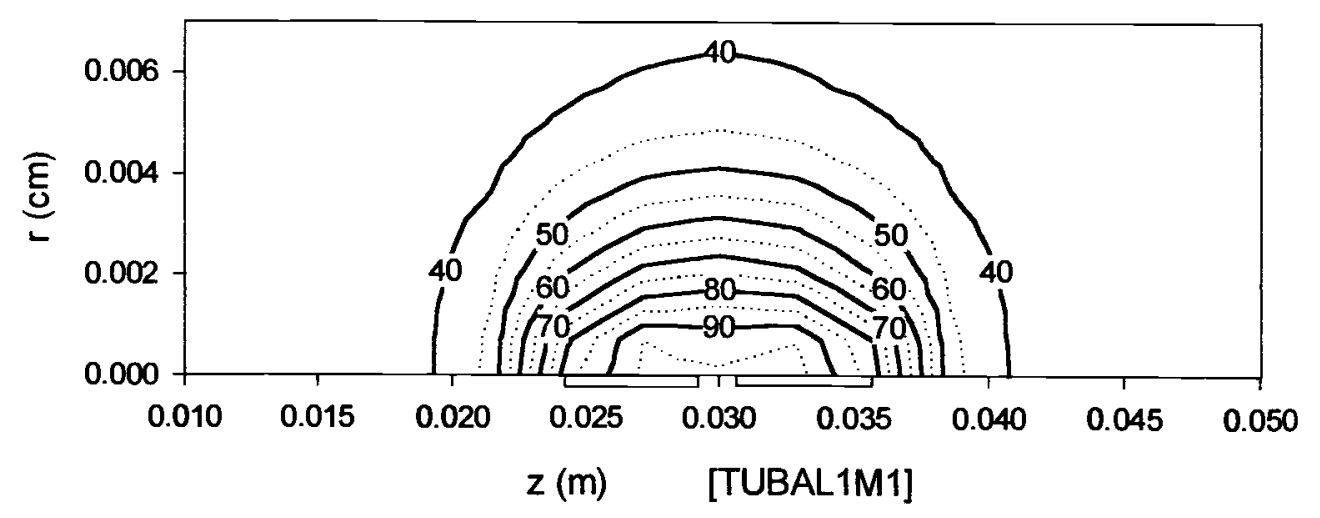

FIGURE 11

Results in a human fallopian tube simulation in cylindrical coordinates. Temperature isotherms at the end of treatment (20 s) for bipolar $R F$ electrodes of $5 \mathrm{~mm}$ length and 3 $\mathrm{mm}$ spacing are shown. Applied voltage at the end of treatment was $25.2 \mathrm{~V}$. The horizontal boxes under the z-axis denote the electrode positions.

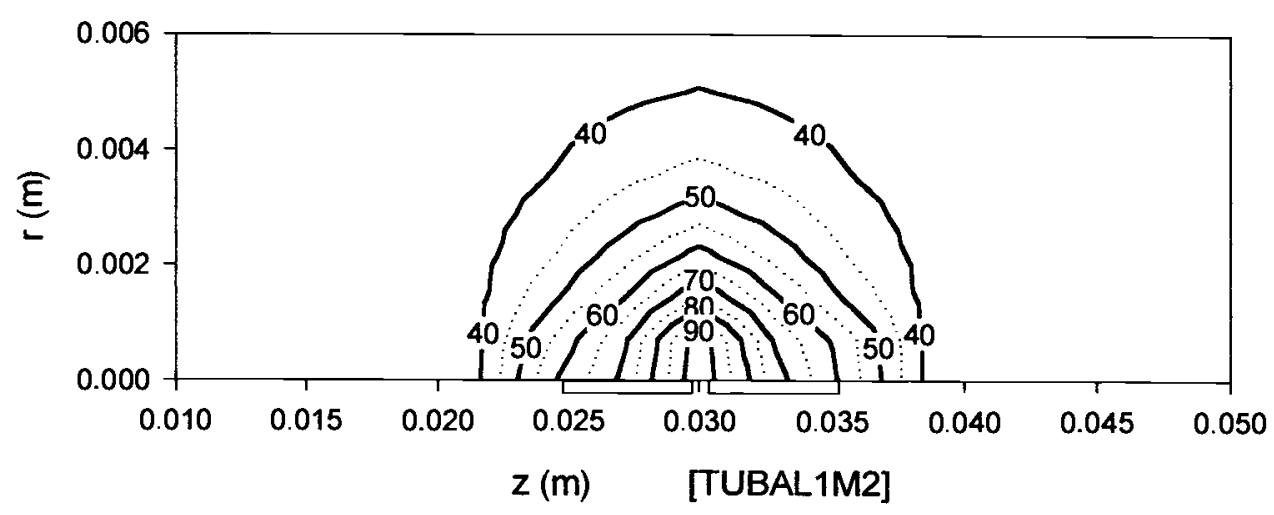

FIGURE 12

Results in a human fallopian tube simulation in cylindrical coordinates. Temperature isotherms at the end of treatment (20 s) for bipolar RF electrodes of $5 \mathrm{~mm}$ length and 1 mm spacing are shown. Applied voltage at the end of treatment was $17.4 \mathrm{~V}$. The horizontal boxes under the z-axis denote the electrode positions. 


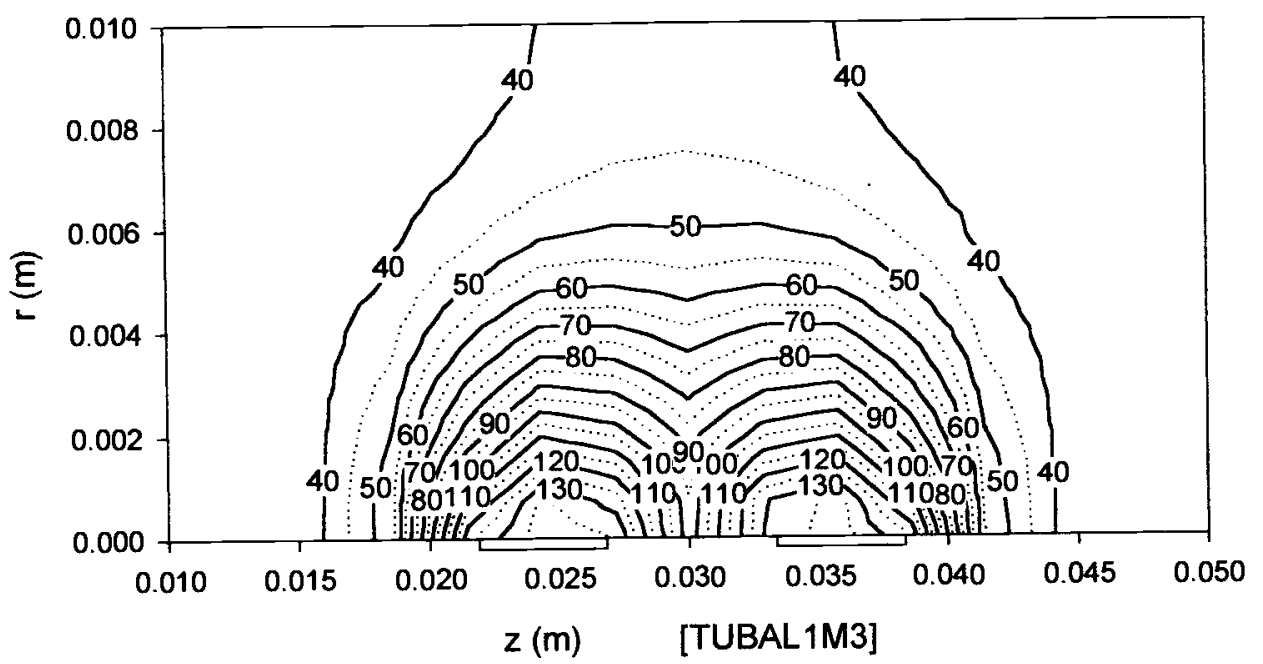

FIGURE 13

Results in a human fallopian tube simulation in cylindrical coordinates. Temperature isotherms at the end of treatment (20 s) for bipolar $R F$ electrodes of $5 \mathrm{~mm}$ length and 7 $\mathrm{mm}$ spacing are shown. Applied voltage at the end of treatment was $30.6 \mathrm{~V}$. The horizontal boxes under the $z$-axis denote the electrode positions.

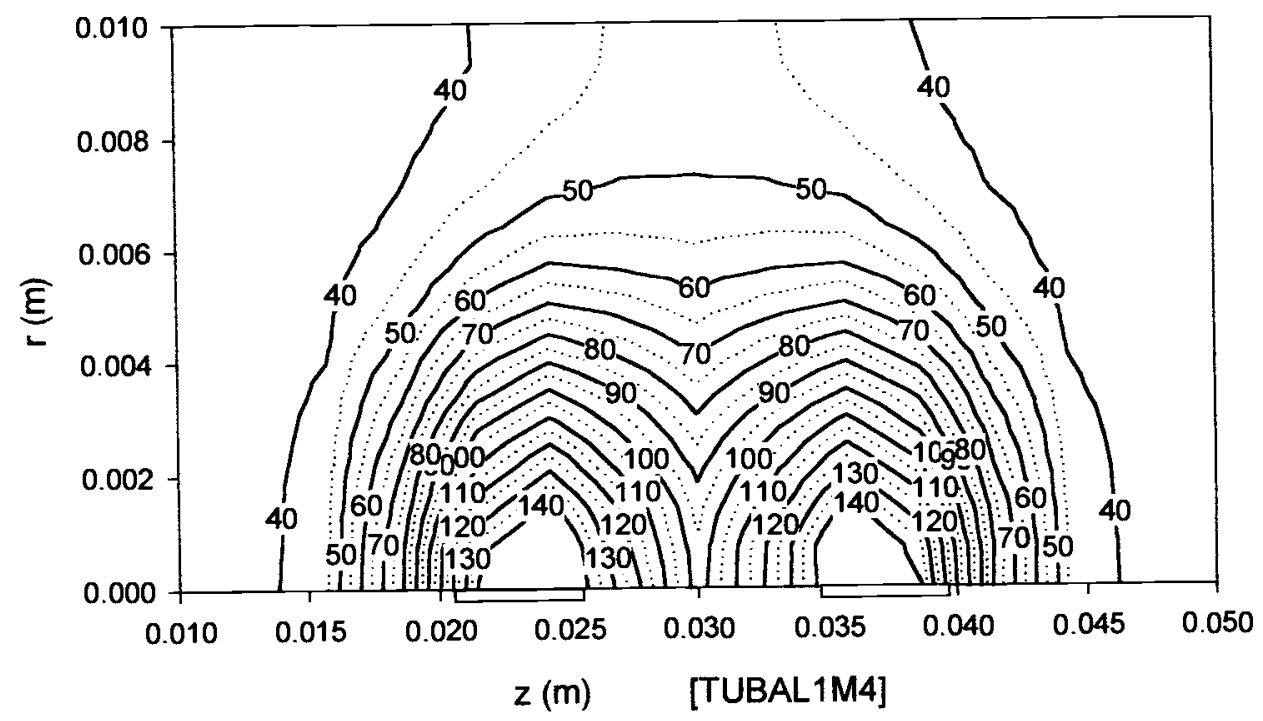

FIGURE 14

Results in a human fallopian tube simulation in cylindrical coordinates. Temperature isotherms at the end of treatment (20 s) for bipolar RF electrodes of $5 \mathrm{~mm}$ length and 9 $\mathrm{mm}$ spacing are shown. Applied voltage at the end of treatment was $20.0 \mathrm{~V}$. The horizontal boxes under the $z$-cxis denote the electrode positions. 


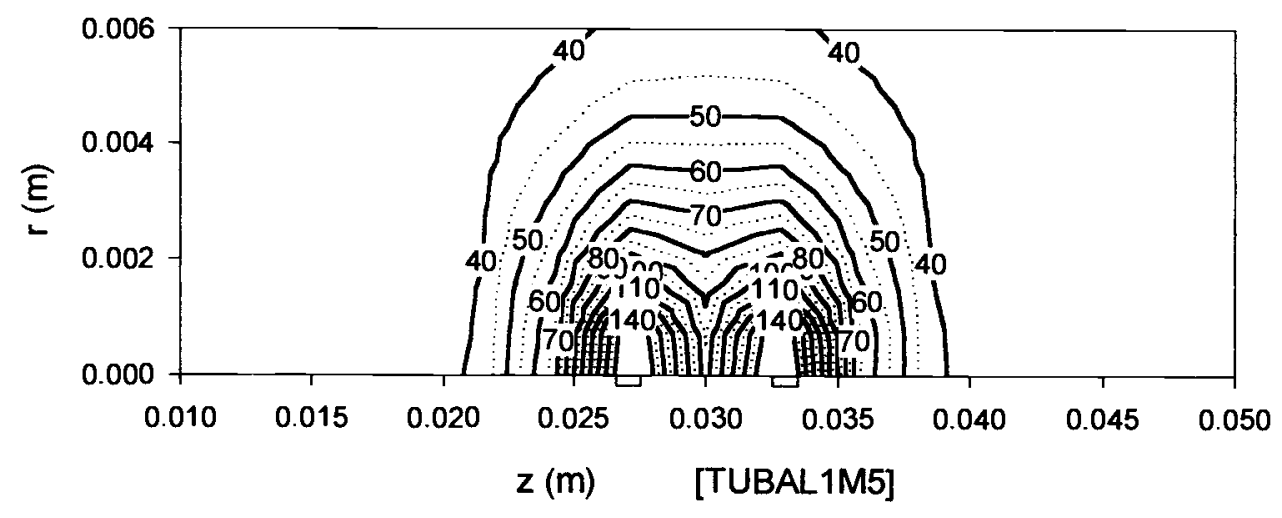

FIGURE 15

Results in a human fallopian tube simulation in cylindrical coordinates. Temperature isotherms at the end of treatment (20 s) for bipolar $R F$ electrodes of $1 \mathrm{~mm}$ length and 5 $\mathrm{mm}$ spacing are shown. Applied voltage at the end of treatment was $33.0 \mathrm{~V}$. The horizontal boxes under the z-axis denote the electrode positions.

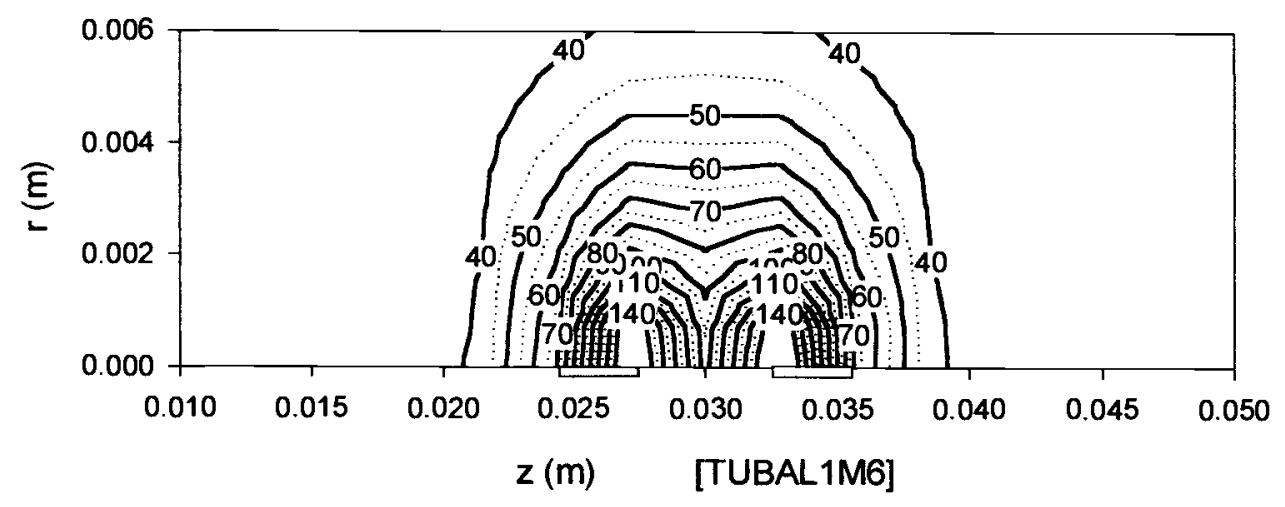

FIGURE 16

Results in a human fallopian tube simulation in cylindrical coordinates. Temperature isotherms at the end of treatment (20 s) for bipolar $R F$ electrodes of $3 \mathrm{~mm}$ length and 5 $\mathrm{mm}$ spacing are shown. Applied voltage at the end of treatment was $32.8 \mathrm{~V}$. The horizontal boxes under the $z$-axis denote the electrode positions. 


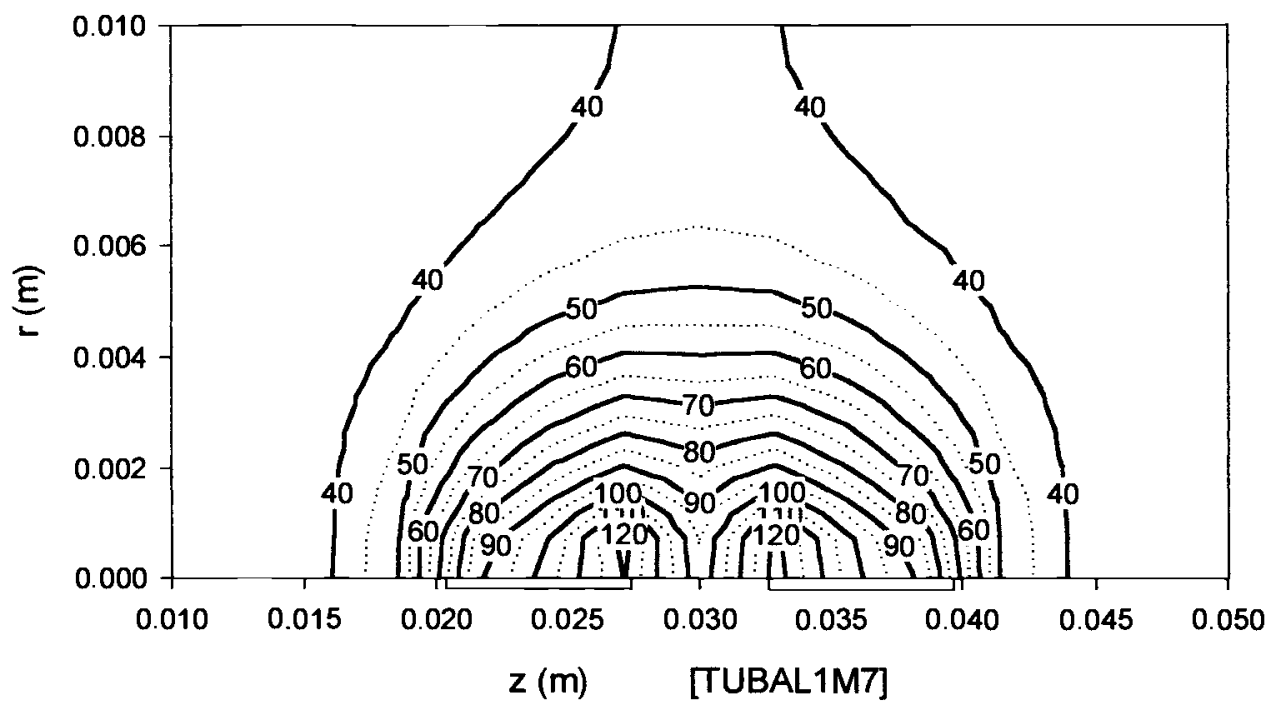

FIGURE 17

Results in a human fallopian tube simulation in cylindrical coordinates. Temperature isotherms at the end of treatment $(20 \mathrm{~s})$ for bipolar $R F$ electrodes of $7 \mathrm{~mm}$ length and 5 $\mathrm{mm}$ spacing are shown. Applied voltage at the end of treatment was $31.4 \mathrm{~V}$. The horizontal boxes under the z-axis denote the electrode positions.

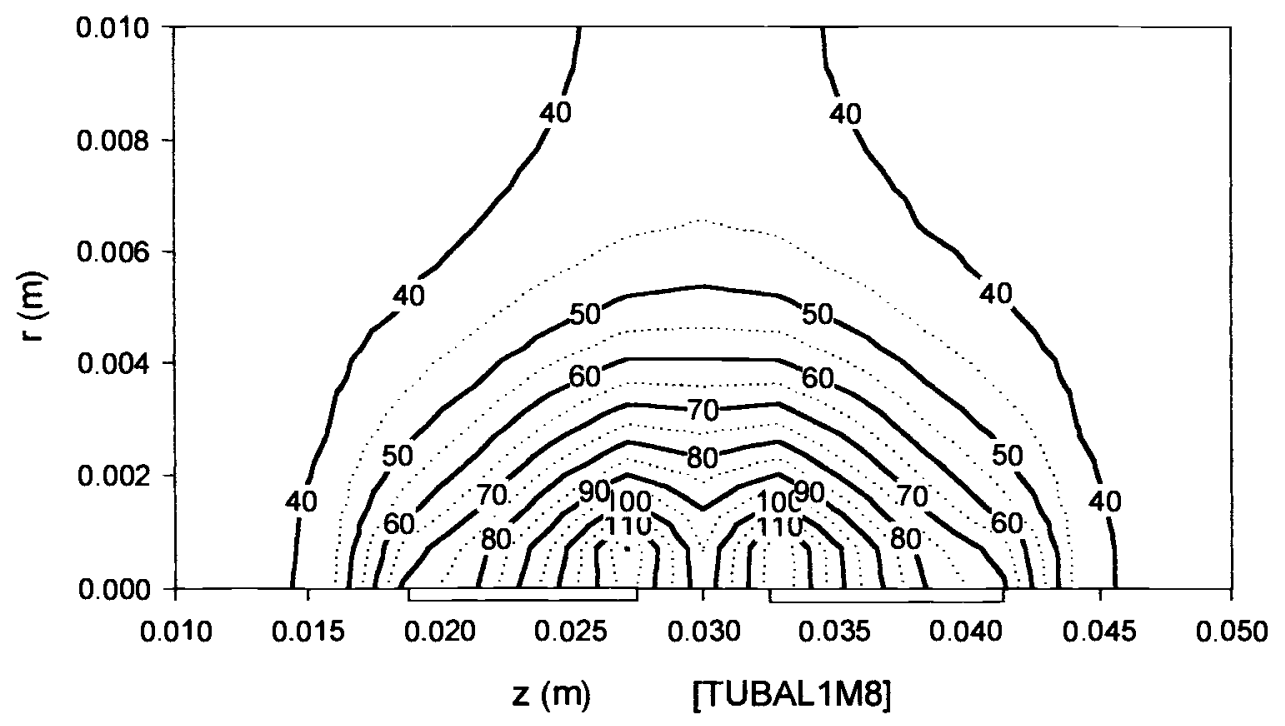

FIGURE 18

Results in a human fallopian tube simulation in cylindrical coordinates. Temperature isotherms at the end of treatment (20 s) for bipolar RF electrodes of $9 \mathrm{~mm}$ length and 5 $\mathrm{mm}$ spacing are shown. Applied voltage at the end of treatment was $31.8 \mathrm{~V}$. The horizontal boxes under the $z$-axis denote the electrode positions. 


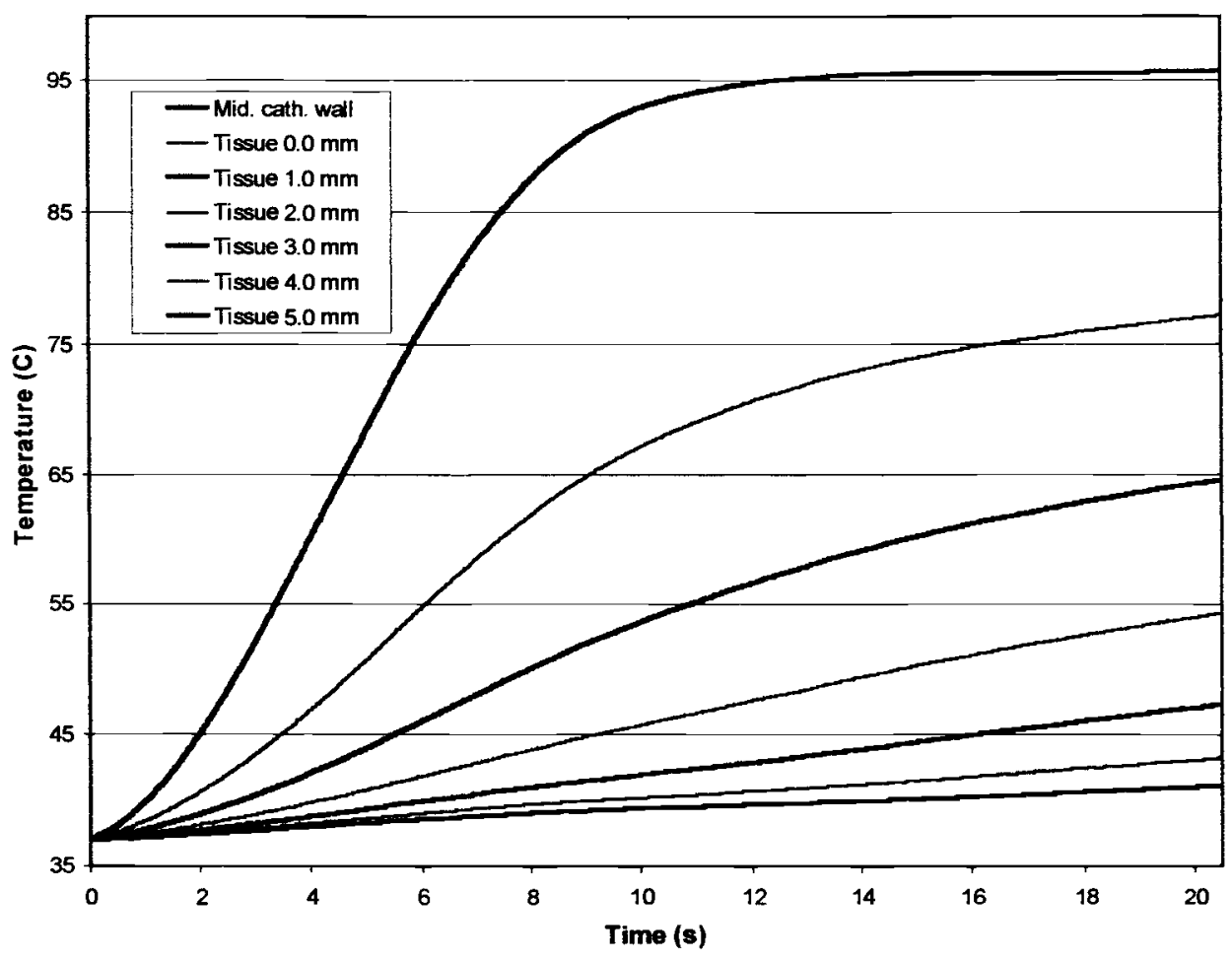

FIGURE 19

Results in a human fallopian tube simulation in cylindrical coordinates. Temperatures are plotted during a $20 \mathrm{~s}$ activation for bipolar RF electrodes of $5 \mathrm{~mm}$ length and $5 \mathrm{~mm}$ spacing. The treatment was controlled by the temperature in the catheter wall between the electrodes (Mid. Cath. wall). This was controlled to achieve $95^{\circ} \mathrm{C}$ in $10 \mathrm{~s}$ and then hold for $10 \mathrm{~s}$. The temperature at $0.0 \mathrm{~mm}$, on the outside of the catheter between the electrodes achieved $77.5^{\circ} \mathrm{C}$ at $20 \mathrm{~s}$. The temperatures at locations 1.0 through $5.0 \mathrm{~mm}$ in tissue, between the electrodes, are also plotted.

\section{DISCUSSION}

\subsection{Overview}

There have been a large number of clinical trials utilizing transcervical techniques in the mechanical, thermal, and chemical domains. Most studies had unacceptable failure rates, or if appearing to be successful, were abandoned due to toxicity, procedural difficulties, or lack of interest by other practitioners that would otherwise fuel widespread use. Often the limited studies appear successful, but larger, 
multicenter clinical trials were never undertaken. Recall that the best laparoscopic techniques claim a failure rate of 2-4 per thousand, so to ascertain global failure rates, a large number of patients must be studied. In some countries, a failure (pregnancy) is a disaster for the parents and litigation could follow.

Historically, failures in clinical trials are related to instrument placement errors, suboptimal energy delivery, and studies going directly to human clinical trials without animal studies for optimal dosage, placement, and histological analysis. The endpoint should be an effective alteration of the tubal mucosa to form a permanent barrier to gamete transfer. Presently, tubal cannulation is routinely performed under hysteroscopic, fluoroscopic, and ultrasonic guidance that replaces a surgical procedure $(53,54)$. It is only a matter of time before tubal sterilization will become widespread hysteroscopically, once a proven technique is available.

The main demand for sterilization procedures are in the countries with large populations and active family planning centers, including China, India, and other Asian countries. Many of these patients are rural based and should receive the most minimally invasive procedure possible, with minimal skill demanded of the practitioner who delivers the treatment. Essential contact with the professional staff should not exceed 15 minutes in order to have potential to treat such a large patient population (18).

\subsection{Challenge of obstructing the tube}

The anatomy of the fallopian tube tends to minimize trauma and promote healing. The intramural segment is surrounded by rich vasculature, supports rapid healing, regrowth and restoration of function with minimal scarring (63). Due to its task of promoting the species, the fallopian tube is especially challenging when operating transcervically.

There were many studies that used thermal techniques to obliterate the lumen and block the tube. Failure occurred due to the inability to standardize and control the delivery of electrical current to the requisite area (64). Quinines et al. (40) summarized the failures of transcervical sterilization by suggesting that failure is often traced to electrocoagulation done in the secretory phase, the size of the electrode, the failure of the power unit, the length of time, and the experience of physician. The patients experienced tolerable discomfort at the time of the application of RF energy.

Early monitoring of thermal techniques were placing a hand on the patient's abdomen to feel warmth (1934) and placing a stethoscope on the abdomen to hear the crackling sound and sizzling $(1878,1968)$. These are essentially crude monitoring techniques to assure that the heat application occurred, but in no way quantified the thermal doe of time and temperature to the treatment zone. Due to inhomogeneities of patient anatomy as well as electrical and thermal tissue properties, a control system is required that both monitors and controls temperatures to assure reproducibility, clinical success, and minimization of complications. In many cases, although power is set, the output is dependent on the tissue impedance and power may actually not be delivered once the tissue is desiccated. A constant power alone will not assure regulation of temperature. That emphasizes the measurement of temperature and control to assure that the minimal thermal dose for obliteration is given. This was shown in Hurst et al (54), 
where in their rabbit mating study, they had success when temperatures were controlled to $95-105^{\circ} \mathrm{C}$ for $20 \mathrm{~s}$ duration.

Other factors also are significant when doing RF ablation. Whether or not the system is monopolar or bipolar will dramatically affect the results. Having bipolar electrodes where the RF current flows entirely inside the fallopian tube and not inadvertently in other delicate structures is a great safety factor. The spacing and length of electrodes will affect the performance of the system in terms of lesion length and maximum temperatures. If temperatures are excessive, steam formation will result and may perforate the tube in an explosive release of pressure. The fit of the RF device in the tube or horn is also critical since RF current delivery depends on direct electrical contact at $500 \mathrm{kHz}$. This could change the amount of circumferential heating. Keeping the time of activation to a minimum will help minimize heating of adjacent structures such as bladder and bowel as thermal conduction spreads the heating field. Presently, the bipolar forceps that are used in the majority of laparoscopic sterilization procedures grasp and apply energy to the outside of the tubes. This is the standard of care today and has yet to be improved upon. The target is obviously in the inside and thus no good evaluation can be done of the inner lumen damage by observing the outside of the tube.

Tucker et al. (48) suggest that the measure of complete tubal destruction should be correlated with of tissue impedance changes or energy delivered. In the study by Hurst et al. (54), impedance did not rise because temperature was well regulated. Measured impedance values actually decreased, because there is a temperature dependence of tissue electrical impedance (55). Placing glucose or other fluids into the horn or tube prior to $\mathrm{RF}$ activation could change results since this could affect current flow.

The fallopian tube has natural peristalsis and thus implants left in place tend to migrate. That forced some users to combine implants with a cautery procedure. The initial inflammatory response may hold the implant better and the fibrosis that ensues will also hold it in place. If the thermal portion alone is successful, the implant will be redundant and unnecessary. Injecting polymers also were problematic since they could migrate or be expelled as a large mass and some broke apart into segments over time. If the advantage of implants is the reversibility potential, the advantage is lost in those procedures where cautery or chemicals and implants are combined and thus damage is more extensive.

There is some conjecture whether or not the fallopian tube needs to be completely blocked or obliterated. If thermally overdosed, the tube may become a charred, rigid, wide open channel, initially following treatment. In the RF treatment described by Hurst et al. (54), the electrodes came out easily following the treatment. The normally closed fallopian tube then reclosed upon removal of the catheter. Some clinical trials showed no pregnancies and some did, even with a hardened polymer in the tube. The no-pregnancy cases may depend on interference with peristalsis. If a thermal treatment is delivered and if the lumen is still patent, the normal mucosal surfaces are destroyed and the natural peristalsis is eliminated. Thus, the tubal environment that nurtures and accepts the egg and sperm movement is destroyed. This may result in pregnancy prevention, although having complete stoppage of sperm and egg passage by elimination of the lumen is preferable. 


\subsection{Complications of treatment}

The complications were often treatment specific. If a metallic implant is placed in the fallopian tube or a polymer injected and then solidified, migration could occur. The loose foreign body could cause infection or adhesions. Women experience slight to moderate cramping pain during coagulation (40). If chemicals are used, such as cyanoacrylate, the toxicity and mutagenicity must be closely studied. Some work found that quinicrine, which was being tested worldwide, caused mutagenicity and would thus not be safe. Injected solutions could enter a blood vessel inadvertently.

In any thermal ablation technique whether hot water is injected, hot pokers inserted into the uterus, or RF, laser or microwave energy is applied, stray heating may take place. The tube is thin in some segments or a device could perforate the tube when inserted and heat completely outside of the tube. The typical target structure would then be the bowel which has very low tolerance for applied heat and may end up in perforation. Darabi Roy et al. (65) reported 4\% major complications and death due to bowel perforation and peritonitis with RF devices. Bowel perforation is a major complication outlined by several authors if bowel is close to the uterine serosa and long treatment times are used (39).

\subsection{Evaluation of results}

In many of the studies, follow-up of the patients involved a clinic visit for tests of fallopian tube patency. Hysterosalpingography is typically used and involves injecting a contrast agent into the fallopian tube. The intramural portion of the tube is most often studied in clinical trials since this is where treatments are preferably done. This part commonly goes into tubal spasm when manipulated and so may appear closed when in fact there is a viable lumen. It is important to evaluate implants that migrate, remove themselves entirely from the fallopian tubes, or become discontinuous in the tube. Implants must be carefully evaluated at defined intervals to assess their status. Some studies showed that during hysterosalpingography, the contrast agent went around the implant and thus outlined a patent lumen. The implant may still interfere with pregnancy so the test may be inconclusive. Another condition may be one where a very tiny lumen persists and the dye will show no patency. If the sperm can still traverse the reduced diameter lumen, an ectopic pregnancy may result. Since the sperm passes but the egg cannot, the pregnancy may end up developing in the fallopian tube, which is lifethreatening. The evaluation of the lumen in animal studies is also challenging since many slides would have to be evaluated to assess continuity down the tube axis. A mating study would provide a better, measurable outcome, especially in rabbits which develop and heal rapidly.

\subsection{Comparative costs of contraception}

One factor that will drive acceptance of a global contraceptive method is cost. Some methods require regular clinic and physician visits for replenishment and examination of devices or effects of oral medications. Direct costs of various contraceptive methods were studied by Ashraf et al. (66). They took into account periods of effectiveness, efficacy rates, rates of adverse reactions, pregnancy costs, abortion costs, miscarriage costs, and clinical outcome. Most women obtain a sterilization procedure in their thirties, so a 15 year usage is calculated, up to the time of menopause. 
Cost per method $=$

Direct cost of device or method $=$

+ direct cost of additional monitoring and medical care

+ direct cost of adverse effects $\mathbf{x}$ rate of incidence

- direct cost of beneficial effects $\mathbf{x}$ rate of incidence

+ cost of failure (pregnancy)

\begin{tabular}{|l|c|c|}
\hline METHOD & COST/YEAR & FAILURE RATE (\%) \\
\hline Vasectomy & 55 & 0.22 \\
\hline Tubal ligation & 118 & 0.42 \\
\hline IUD & 150 & 0.6 \\
\hline Levonorgestrel implants & 202 & 0.2 \\
\hline Oral contraceptives & 456 & 3.6 \\
\hline Condoms & 776 & 12.0 \\
\hline Diaphragm & 1147 & 15.1 \\
\hline
\end{tabular}

TABLE 3

The summary of the work by Ashraf et al. (1994) is shown. Basically, a breakdown of the cost per year for the most common forms of contraception with resultant failure rate is enumerated.

As seen in Table 3, devices like the diaphragm and condoms are costly, whereas a vasectomy or tubal ligation are least expensive, when use is considered over the reproductive lifetime of the sexual partners. Although the table argues for vasectomy as the least expensive technique, men will be reluctant to have the procedure and will instead rely on techniques done for women.

\subsection{Ablation numerical model}

A versatile model should have the capability of inputting changing tissue parameters when temperatures are high enough to affect results, and thus will better predict tissue thermal events in biological systems. If the tissue is pathological and has different thermal properties or perfusion, these can be input. Trends show that as temperature rises, electrical conductivity increases, but not exactly as $2 \% /{ }^{\circ} \mathrm{C}$ (58) estimates predict (67).

Many studies have been done in a rabbit model. If the fallopian tube is compared with human, that rabbit has an extensive fat layer that surrounds the lumen, whereas the human does not. The difference in electric field, power distribution, and temperature distribution are obvious, when comparing the rabbit to human tubes. 
The development of the devices shown here can be greatly aided by numerical simulations that allow parameter changes such as material types and thicknesses, electrode lengths, thickness and spacing, and tissue properties. The design process may be sped up by letting the model compare various designs prior to prototyping and bench testing. Hopefully, application of a good model may reduce time to commence clinical trials and make the devices available to the medical treatment community so that patients can ultimately benefit.

\section{CONCLUSIONS}

Many techniques have been tried for over 150 years to achieve transcervical sterilization (69). Currently, as the new millenium is entered, thermal techniques have the greatest potential due to the lack of a foreign body being left behind and initial studies that show success in rabbit and feline models. The challenges that remain are substantial: 1) small devices that can enter fallopian tubes of the majority of women by less skilled clinic personnel; 2) safety in thermal spread such that bowel is not thermally injured, resulting in perforation and potentially a fatal outcome; 3 ) simple and fast procedures that assist in the entry of dwevice into the fallopian tube and monitoring of the treatment location and thermal dose applied; and lastly 4) equal or exceeding the pregnancy outcome of today's techniques $(0.4 \%$ failure).

\section{ACKNOWLEDGEMENTS}

Dr. Sharon Thomsen, formerly of MD Anderson Cancer Center and presently at the University of Texas at Austin, is gratefully acknowledged for histological examination analysis of human, rabbit, and mini-pig fallopian tube, boundless knowledge, and frequent inspiration. Dr. Roop Mahajan is acknowledged for thermal conductivity measurements. Lastly, Dr. Brad Hurst is cited for his devotion to the project and continuous and optimistic support.

\section{REFERENCES}

1. K. Limpaphayom, "Sterilization," Current Opinion in Obstet. Gynecol. 3, pp. 501$505,1991$.

2. J.D. Sheldon and J.J. Speidel, Need for nonsurgical sterilization in Zatuchni GI, Shelton JD, Goldsmith A, Sciarra JJ (eds) Female Transcervical Sterilization, Harper and Row, Philadelphia, pp. 1-6, 1983.

3. E. Kessel and S.D. Mumford, "Potential demand for voluntary sterilization in the 1980s: the compelling need for a non-surgical method," Fertil. Steril. 37, pp. 725733, 1982.

4. E.W. Wilson, "The development of new technologies for female sterilization: conclusions and recommendations for research," Int. J. Gynecol. Obstet. 51(suppl), pp. S71-S74, 1995.

5. E.W. Wilson, "The evolution of methods for female sterilization," Int. J. Gynecol. Obset. S3-S13, 1995.

6. S.S. Thatcher, "Hysteroscopic sterilization," Obstet. Gynecol. Clin. North Am. 15, pp. $51-59,1988$. 
7. T.G. Vancaillie, C.A. Eddy, and L. Faufe, "A new method of transcervical female sterilization: preliminary results in rabbits," Fertility. Steril. 51, pp. 335-338, 1989.

8. M. Rocca, M. el Habashy, S. Nayel, and A. Madwar, "The intramural segment and the uterotubal junction, an anatomic and histologic study," Int. J. Gynecol. Obstet., pp. 343-349, 1989.

9. E.W. Wilson, "Sterilization," Bailliere's Clin. Obstet. Gynecol. 10, pp. 103-119, 1996.

10. D. Pantaleoni, "Hysteroscopy through a transparent rubber balloon in patients with carcinoma of the uterine endometrium," Acta. Obstet. Gynecol. Scand. 42, p. 284, 1963.

11. J. Hamou, F. Gasparri, G.F. Scarselli, L. Mencaglia, A. Perino, P. Quartararo, and Z. Cittadini, "Hysteroscopic reversible tubal sterilization," Acta. Europaena Fertilitatis 15, pp. 123-1259, 1984.

12. J.M. Cooper, H.S. Rigberg, R. Houck, and M. Aiken, "Incidence, significance and remission of tubal spasm during attempted hysteroscopic tubal sterilization," $J$. Reprod. Med. 30, pp. 39-42, 1985.

13. J. Brundin, "Transcervical sterilization in the human female by hysteroscopic application of hydrogelic occlusive devices into the intramural parts of the fallopian tubes: 10 years experience of the P-block," Eur. J. Obstet. Gynecol. Reprod. Biol. 39, pp. 41-49, 1991.

14. T. Schmitz-Rode, P.L. Ross, A.S. Thurmond, R.W. Gunther, and J. Rosch, "Experimental nonsurgical female sterilization: transcervical implantation of microspindles in fallopian tubes," J. Vasc. Interven. Radiol. 5, pp. 905-910, 1994.

15. P.L. Ross, A.S. Thurmond, B.T. Uchida, M.K. Jones, R.M. Scanlan, and E. Kessel, "Transcatheter tubal sterilization in rabbits: technique and results," Invest. Radiol. 29, pp. 570-573, 1994.

16. J.H. Post, J.F. Cardella, R.P. Wilson, J.W. Griffith, P.S. Fox, P.N. Waybill, and J.R. Hills, "Experimental nonsurgical transcervical sterilization with a custom designed platinum microcoil," J. Vascular Inteventional Radiol. 8, pp. 113-118, 1997.

17. R.S. Neuwirth, R.M. Richart, C. Israngkun, R.U. Levine, and S. Phaosavsadi, Hysteroscopic sterilization, In Sciarra JJ, Butler JC, Spiedel JJ (eds), Hysteroscopic sterilization, Intercontinental Medical Books, New York, pp. 121-129, 1973.

18. R.M. Richart, R.S. Neuwirth, C. Israngkun, and S. Phaosavasdi, "Female sterilization by electrocoagulation of tubal ostea using hysteroscopy," Am. J. Obstet. Gynecol. 117, pp. 801-804, 1973.

19. R.N. Merchant, S.R. Prabhu, and E. Kessel, "Clinopathological study of fallopian tube closure after single transcervical insertion of quinicrine pellets," Int. J. Fertil. 40, pp. 47-54, 1995.

20. A.A. El Kady, H.S. Nagib, and E. Kessel, "Efficacy and safety of repeated transcervical quinicrine pellet insertions for female sterilization," Fertil. Steril. 59, pp. 301-304, 1993.

21. L.E. Laufe, D.C. Sokal, L.P. Cole, D. Shoupe, and R.S. Schenken, "Phase I prehysterectomy studies of the transcervical administration of quinicrine pellets," Contracept. 54, pp. 181-186, 1996.

22. J. Shuber, "Transcervical sterilization with use of methyl 2-cyanoacrylate and a newer delivery system (the FEMCEPT device)," Am. J. Obstet. Gynecol. 160, pp. 887-889, 1989.

23. R.S. Neuwirth, "Update on transcervical sterilization," Int. J. Gynecol. Obstet. 51(suppl), pp. S23-S28, 1995. 
24. A.S. Sonmez, I. Aruh, R.C. Dunn, R.H. Kaufman, and C.J. Chuong, "Sterilization with fibrin sealant in a rabbit uterine horn model," Am. J. Obstet. Gynecol. 177, pp. 573-578, 1997.

25. A. Erb, Hysteroscopic tubal occlusion procedure with formed-in-place silicone plugs: instruments and technique, In Sciarra JJ, Butler JC, Spiedel JJ (eds), Hysteroscopic sterilization, Intercontinental Medical Books, New York, pp. 245-254, 1973.

26. F.D. Loffer, "Hysteroscopic sterilization with the use of formed-in-place silicone plugs," Am. J. Obstet. Gynecol. 149, pp. 261-267, 1984.

27. A.J. Maubon, A.S. Thurmond, A. Laurent, J.E. Honiger, R.M. Scanlan, and J.P. Rouanet, "Selective tubal sterilization in rabbits: experience with a sclerosing agent," Radiol. 193, pp. 721-723, 1994.

28. T.S. Moulding and P.S. Sirotta, "Hot water as a tubal occluding agent," Contraception 19, pp. 433-442, 1979.

29. V. Rimkus and K. Semm, Sterilization by carbon dioxide hysteroscopy, In Sciarra JJ, Butler JC, Spiedel JJ (eds), Hysteroscopic sterilization, Intercontinental Medical Books, New York, pp. 75-84, 1973.

30. B.H. Sheares, "Sterilization of women by intra-uterine electro-cautery of the uterine cornua,“ J. Obstet. Gynecol. 65, pp. 419-427, 1958.

31. R.L. Dickenson, "Simple sterilization of women by cautery stricture at the uterine tubal openings, compared with other methods," Surg. Gynecol. Obstet. 23, p. 203, 1916.

32. C. Schroeder, "Uber den ausban und die leistungen der hysteroskopie," Arch. Gynaekol. 156, pp. 407, 1934.

33. M. N. Hyams ,"Sterilization of the female by coagulation of the uterine cornua," Am. J. Obstet. Gynecol. 28, pp. 96-101, 1934.

34. K. Pasricha, "Sterilization by cornual cautery, “ Am. J. Obstet. Gynecol. 100, pp. 877-878, 1968.

35. H.J. Lindemann, Transuterine tubal sterilization by $\mathrm{CO}_{2}$ hysteroscopy, In Sciarra JJ, Butler JC, Spiedel JJ (eds), Hysteroscopic sterilization, Intercontinental Medical Books, New York, pp. 61-73, 1973.

36. O. Sugimoto, Hysteroscopic sterilization by electrocoagulation, In Sciarra JJ, Butler JC, Spiedel JJ (eds), Hysteroscopic sterilization, Intercontinental Medical Books, New York, pp. 107-120. 1973.

37. R.Q. Guerror, R.A. Ramus, and A.A. Duran, "Tubal electrocauterization under hysteroscopic control," Contraception 7, pp. 195-201, 1973.

38. G.R. Quinones, D.A. Alvarado, and R.R. Aznar, "Tubal occlusion by electrocoagulation under hysteroscopy," Int. J. Fertil. 18, pp. 167-173, 1973.

39. G.R. Quinones, A. Alvarado, and Y.E. Le, Hysteroscopic sterilization: follow-up of 800 cases In Sciarra JJ, Droegemueller W, Spiedel JJ (eds), Advances in Female Sterilization Techniques, Harper and Row, Hagerstown, pp. 162-168, 1976.

40. G.R. Quinones, A.D. Alvarado, and E. Ley, "Tubal electrocoagulation under hysteroscopic control (350 cases)," Am. J. Obstet. Gynecol. 121, pp. 1111-1113, 1975.

41. L.A. Cibils, "Permanent sterilization by hysteroscopic cauterization," Am. J. Obstet. Gynecol. 121, pp. 513-520, 1975.

42. C.M. March and R. Israel, "A critical appraisal of hysteroscopic tubal fulguration for sterilization," Contraception 11, pp. 261-269, 1975. 
43. W. Droegemueller, B.E. Greer, J.R. Davis, E.L. Makowski, M. Chvapil, and A. Pollard, "Cryocoagulation of the endometrium at the uterine cornua," Am. J. Obstet. Gynecol. 131, pp. 1-9, 1978.

44. J.R. Brumstead, G. Shirk, M.J. Soderling, and T. Reed, "Attempted transcervical occlusion of the fallopian tube with the Nd:YAG laser," Obstet. Gynecol. 77, pp. 327-328, 1991.

45. S.A. Grochmal, A. Weekes, and D. Garrait, "Hysteroscopic assisted laser tubal sterilization (H.A.L.T.S.), a three-year follow-up," Proc. Am. Assoc. of Gynecol. Laparosc., 1994.

46. C.R. Yoon, T.M. Wheeless, and T.M. King, "A preliminary report on a new laparoscopic sterilization approach: the silicone rubber band technique," $\mathrm{Am} . \mathrm{J}$. Obstet. Gynecol. 120, pp. 132-136, 1974.

47. J. Hulka, J.P. Mercer, and J.T. Fishbone, "Spring clip sterilization: one year followup of 1079 cases," Am. J. Obstet. Gynecol. 125, pp. 1039-1043, 1976.

48. R.D. Tucker, J.A. Benda, A. Mardan, and T. Engel, "The interaction of electrosurgical bipolar forceps and generators on an animal model of fallopian tube sterilization," Am. J. Obstet. Gynecol. 165, pp. 443-449, 1991.

49. K. Kato, K. Buhler, C. Klessen, R. Koch, A.E. Schlinder, "A computer based, temperature controlled bipolar electrocoagulation system," Eur. J. Obstet. Gynecol. Reprod. Biol. 68, pp. 119-122, 1996.

50. K. Kato, M. Reich, K. Buhler, and A.E. Schindler, “A computer based, temperature controlled bipolar electrocoagulation system: II optimal temperature and coagulation time," Eur. J. Obstet. Gynecol. Reprod. Biol. 78, pp. 103-107, 1998.

51. S. Trembly, P. Manganiello, and J. Hoopes, "Microwave occlusion of the rabbit uterine horn," in Surgical Applications of Energy, Ryan TP (ed), 3249, pp. 50-60, 1998.

52. P. D. Manganiello, B.L. Sueoka, D. R. Valentine, and T.P. Hoopes, "A bipolar radiofrequency catheter fails to occlude a feline uterine horn: a model for fallopian tube occlusion," J. Am. Assoc. Gynecol. Laparosc. 5, pp.269-273, 1998.

53. B.S. Hurst, S. Thomsen, K. Lawes, T. Ryan, "Controlled radiofrequency endotubal sterilization," Adv. Contracep. 14, pp. 147-152, 1998.

54. B.S. Hurst, T. Ryan, S. Thomsen, and K. Lawes, "Computer-controlled bipolar endotubal sterilization is successful in a rabbit model," Fertil. Steril. 71, pp. 765$770,1999$.

55. J.S. Dadd, T.P.Ryan, and R.C. Platt, "Tissue impedance as a function of temperature and time," Biomed. Scien. Instrum. 32, pp. 205-214, 1996.

56. S.A. Saparetto and W.C. Dewey, "Thermal dose determination in cancer therapy," Int. J. Rad. Oncol. Biol. Phys. 10, pp. 787-800, 1984.

57. T.P. Ryan, R.C. Platt, J.S. Dadd, and S. Humphries, "Tissue electrical properties as a function of thermal dose for use in a finite element model," Advances In Heat And Mass Transfer In Biotechnology, HTD-Vol. 355/BED Vol.37, pp. 167-171, 1997.

58. H.P. Schwan and K.R. Foster, "RF-field interactions with biological systems: electrical properties and biophysical mechanisms," Proc. IEEE 68, pp. 104-113, 1980.

59. S. Labonte, "Numerical model for radio-frequency ablation of the endocardium and its experimental validation," IEEE Trans. Biomed. Engin. 41, pp. 108-115, 1994.

60. P.A. Patel, J.W. Valvano, J.A. Pearce, S.A. Prahl, and C.R. Denham, "A self-heated thermistor technique to measure effective thermal properties from the tissue surface," Tran. ASME 109, pp. 330-335, 1987. 
61. S. Humphries, R.C. Platt, and T.P. Ryan, "Finite-element codes to model electrical heating and non-linear transport in biological media," Advances In Heat And Mass Transfer In Biotechnology, HTD-Vol. 355/BED Vol. 37, pp. 131-134, 1997.

62. H.H. Pennes, "Analysis of tissue and arterial blood temperatures in resting forearm," J. Appl. Physiol. 1, pp. 93-122.

63. J.M. Cooper, "Hysteroscopic sterilization," Clin. Obstet. Gynecol. 35, pp. 282-298, 1992.

64. J.J. Sciarra and L. Keith, "Hysteroscopic sterilization," Obstet. Gynecol. Clin. North Am. 22, pp. 581-589, 1995.

65. K.F. Darabi, K. Roy, and R.M. Richart, Collaborative study on hysteroscopic sterilization procedures: Final report, in Sciarra JJ, Zatuchni GI, Speidel JJ (eds), Risks, benefits and controversies in fertility control, Harper and Row, Hagerstown, p.81, 1978.

66. T. Ashraf, S.B. Arnold, and M. Maxfield, "Cost-effectiveness of Levonorgestrel subdermal implants, comparison with other contraceptive methods available in the United States,". J. Reprod. Med. 37, pp. 791-798, 1994.

67. M.J. Moskowitz, T.P. Ryan, K.D. Paulsen, and S.E. Mitchell, "Clinical implementation of electrical impedance tomography with hyperthermia," Int. J. Hyperthermia 11, pp. 141-149, 1995.

68. J. Kocks, "Eine neue methode der sterilization der frauen," Zentbl. Gynakol. 26, p. $617,1878$.

69. R. Froriep, "Zur vorbeugung der notwendigkeit des kaiserschnittes und der perforation notizen," Geb. Nat. Heilk. p. 211, 1849.

70. R.S. Nuewirth, R.M. Richart, L.R. Bolduc, and R.E. Krall, "Trials with the FEMCEPT method of female sterilization and experience with radiopaque methylcyanoacrylate," Am. J. Obstet. Gynecol. 145, pp. 948-954, 1983.

71. V.M. Merchant, V. Doctor, S.S. Thaku, M. Sinha, C.L. Jhaveri, E. Kessel, and S.D. Mumford, "Clinico-pathological study of fallopian tubes after transcervical insertion of quinicrine hydrochloride pellets," Adv. Contracept. 2, pp. 79-90, 1986.

72. T. P. Ryan, Methods of thermal modeling and their impact on IHT treatment planning, IN Seegenschmiedt MH, Sauer R (eds), Interstitial and intracavitary thermoradiotherapy, Springer-Verlag, Berlin, pp. 95-116, 1993.

73. K.R. Diller and T.P. Ryan, "Heat Transfer in Living Systems: Current Opportunities," J. Heat Transfer 120, pp. 810-829, 1998.

Email tryan@ieee.org; TEL 9082182114 ; FAX 9082183481 